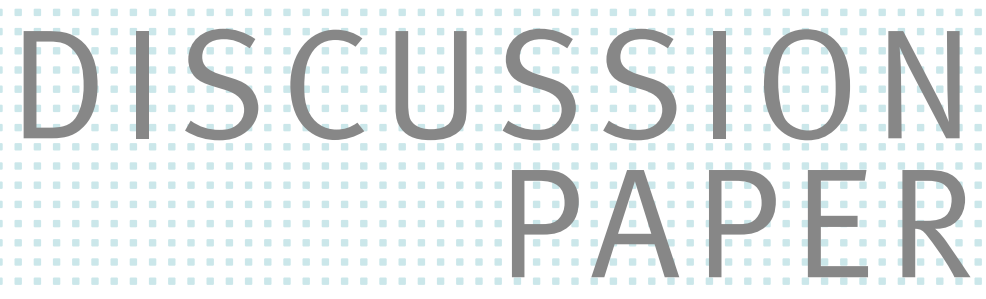

// JAN ABRELL AND MIRJAM KOSCH

The Impact of Carbon Prices on Renewable Energy Support 


\title{
The impact of carbon prices on renewable energy support
}

\author{
Jan Abrell ${ }^{\mathrm{a}}$, Mirjam Kosch ${ }^{\mathrm{b}}$ \\ ${ }^{a}$ Department of Environmental and Resource Economics, Environmental Management, \\ ZEW Leibniz Centre for European Economic Research, jan.abrell@zew.de \\ ${ }^{b}$ Potsdam Institute for Climate Impact Research (PIK), mirjam.kosch@pik-potsdam.de
}

\begin{abstract}
This paper examines how optimal renewable energy (RE) support (RES) policies need to be adjusted to account for carbon prices. We show theoretically and empirically that changing carbon prices requires adjusting $\mathrm{RE}$ production subsidies due to two different motives: First, RE premiums need to be reduced to reflect the carbon value embedded in the market price. Second, RE premiums and feed-in tariffs need to be adjusted once a fuel switch away from coal towards gas power occurs. This adjustment is necessary to account for changes in the marginal external benefit of RE. For the case of the UK, we estimate the optimal RE subsidies and their adjustments due to a fuel switch. Furthermore, we use numerical simulations to analyze the impact of varying carbon prices on optimal RES. We show that the necessary adjustment due to a fuel switch is empirically rather small, whereas RE premiums must be phased out with increasing carbon prices due to the increasing reflection of the carbon cost in the electricity market price. Finally, a fuel switch increases solar-induced abatement, whereas it wind-induced abatement is rather invariant to a fuel switch. Yet, the differentiation of RE subsidies between wind and solar power is modest.
\end{abstract}

Keywords: Renewable promotion, Carbon pricing, Electricity generation JEL: Q41, Q42, Q58

\section{Introduction}

Greenhouse gases from electricity generation are a main driver of man-made climate change. To achieve decarbonization of the power sector, two major regulatory approaches are used. Carbon pricing and renewable energy support (RES) subsidizing renewable energy (RE) generation. Although from an economist's perspective a price on carbon emissions is the preferred instrument, RES historically gained greater political support. Nevertheless, carbon pricing is becoming more and more popular leading to an increase of emissions covered (Worldbank, 2020) and increasing carbon prices. As an example, prices in the European Emissions Trading System (EU ETS) increased from below $5 € / \mathrm{tCO}_{2}$ in 2017 to over $25 € / \mathrm{tCO}_{2}$ in mid 2020 . Increasing carbon prices in a regulatory setting with high RES raise the main question of this article: How does RES need to be adjusted once external cost of carbon emissions are increasingly priced? 
Carbon prices and RE generation reduce emissions through different channels: Carbon pricing policies alter the relative cost of fossil generation. This can change the ordering of power plants along the supply curve, i. e., lead to a switch from (dirty) coal to (cleaner) gas generation. RE promotion incentivizes investments in carbon-neutral technologies. Once installed, they produce electricity at near zero marginal cost and replace fossil generators with high marginal cost. At the same time, there are interactions between the two instruments.

In this paper we investigate the interactions between RE support and carbon pricing policies along two main questions: How does a carbon price change the emissions impact of wind and solar generation? What are the implications of carbon prices for the optimal support of RE generation? To address these questions, we first analytically derive (i) the impact of carbon prices on the emission offset of RE and (ii) the optimal RE support in a world with carbon prices. We then empirically estimate the impact of a fuel switch from coal to gas generation on RE-induced abatement and derive the change in optimal RE subsidies. Finally, we use a numerical model to analyze the impact of increasing carbon prices on RE subsidies.

From a theoretical perspective, the magnitude of abatement induced by one unit of RE generation, i. e., its environmental value, is not fixed, but given by the carbon intensity of the marginal plant which is replaced. This, in turn, depends on carbon pricing policies which can change the ordering of power plants along the supply curve. In other words, a carbon tax makes coal-fired generation more expensive, while gas-fired generation becomes relatively cheaper. Consequently, there is a possible interaction between the emissions impact of the RES and carbon pricing policies: If a carbon price is sufficiently high to induce a fuel switch, i. e. change the marginal generator, it changes the environmental value of $\mathrm{RE}$ generation.

However, RE-induced abatement not only depends on the merit order, but also on time-varying demand. More specific, the point of intersection between the supply and the demand curve determines the marginal generator and consequently marginal emissions. Given that wind and solar are - due to their distinctive availability profiles - producing during different demand periods, they differ regarding their emissions impact, which is also differently affected by a carbon price.

To analyze the impact of carbon pricing on optimal RE promotion, we analyze two different policies: premiums and feed-in tariffs. Callaway et al. (2018) and Abrell et al. (2019c) show that optimal feed-in tariffs reflect the emissions avoided evaluated at the social cost of carbon as well as avoided operating cost. In contrast, the optimal RE premium reflects only the value of avoided external cost. In this paper, we extend these analyses deriving the impact of carbon prices on RE subsidies. We find that introducing or increasing carbon prices requires adjusting RE promotion due to different motives. First, RE premiums that are paid on top of the market price need to be adjusted to reflect the increased carbon value embedded in the market price. An increased carbon price leads to an increased reflection of external cost in the market price. Thus, the optimal RE premium needs to be decreased to grant a subsidy equal to the remaining external cost avoided, i.e., the marginal external benefit net of the external cost already priced. Such an adjustment is not necessary in the case of a feed-in tariff as RE production is not exposed to the market price. Second, both $-\mathrm{RE}$ premiums and feed-in tariffs — need to be adjusted once a fuel switch 
occurs. This is necessary to account for the change in the marginal external benefit of RE sources induced by the change in the merit-order curve.

The empirical analysis focuses on the change in marginal emission offsets of wind and solar power induced by a fuel switch. We estimate the impact for the UK power sector, which implemented extensive RES schemes and at the same time imposed an additional carbon tax, the so-called Carbon Price Support (CPS), on top of the EU ETS. This price in combination with decreasing natural gas prices induced a fuel switch away from coal-fired power plants. For the analysis, we use a rich data set of the years 2015 and 2016 of the UK power market with hourly generation and capacity availabilities, daily coal, gas, EUA and CPS prices, and daily mean temperature. To estimate the impact of wind and solar on coal and gas generation, we use a regression model which allows the coefficients to vary between two different fuel price regimes: During the cheap coal regime coal generation is on average cheaper than gas, during the fuel switch regime gas generation is on average cheaper than coal. We then use the estimated impacts on fossil generation to calculate the change in abatement impacts as well as optimal feed-in tariffs and RE premiums.

We make three main observations. First, we find that carbon prices increase solar-induced abatement by around $8 \%$, whereas wind-induced abatement remains constant. For both technologies, the impact on the differentiation of optimal subsidy payments between RE is rather small. Second, external cost reflected in the market price substantially reduce optimal $\mathrm{RE}$ premiums to less than half of the marginal external benefit. Third, feed-in tariffs for wind and solar need to be adjusted by a decrease of less than $8 \%$ due to a fuel switch. In contrast, optimal premiums increase by about $8 \%$ for solar and remain constant for wind, corresponding to the change in abatement.

Our estimation allows to calculate the impact of a fuel switch on optimal RE subsidies. As carbon prices are relatively stable in our sample, we additionally use a numerical model to analyze the impact of varying carbon prices on optimal RES. The numerical model mimics the UK wholesale market depicting each coal and gas-fired plant and clearing the market for each hour in the sample. Holding natural gas and coal prices constant at their level at the beginning of our sample period, we simulate the impact of increasing carbon prices. This allows us to analyze adjustments of optimal RES solely caused by an increase in carbon prices. We show that the adjustment of feed-in tariffs due to an increase in the marginal benefit of $\mathrm{RE}$ sources is relatively modest. In contrast, RE premiums must be phased out with increasing carbon prices. The reason is that due to the reflection of carbon cost in the electricity market price, $\mathrm{RE}$ receive the (increasing) carbon value through the price. Increasing carbon prices thus reduce the optimal RE premiums and eventually make them redundant.

Our results are relevant for the political debate about increasing carbon prices in the electricity sector. First, our analytical results imply that when $\mathrm{RE}$ promotion is designed using premiums, an increase in carbon prices requires decreasing premium rates. As with increasing carbon prices external costs are increasingly reflected in the market price, a smaller part of the external benefit of RE promotion needs to be granted using premiums. This is also confirmed by our empirical results, which show that the reflection of the carbon tax in the electricity price reduces optimal premium payments by more than half compared to a situation where we do not account for the carbon value reflected in the market price. Second, our results imply that changes in the merit-order curve 
lead to a change in optimal RE premiums and feed-in tariffs. However, we estimate these adjustments to be rather small. The same is true for the optimal differentiation of subsidies across RE sources: Given that the heterogeneity of the marginal emission offsets across RE sources is rather modest, the required differentiation is small.

With our analysis we contribute to three related strands of literature. First, there is recent literature on the optimal design of RES policy. Abrell et al. (2019c) derive optimal RE premiums and feed-in tariffs in the absence of carbon pricing. They find, that from a theoretical perspective optimal RE subsidies should be differentiated to reflect the different environmental effectiveness of RE sources. Yet, in an empirical simulation model for the German power market, this differentiation turns out to be small. Callaway et al. (2018) show for the US that the variation of environmental effectiveness is small within a region but varies substantially across regions. They therefore propose to differentiate RE and energy efficiency subsidies across regions. Abrell et al. (2019b) and Lamp \& Samano (2020) extend these arguments in the presence of storage facilities avoiding curtailment of RE sources and for ancillary service market incomes. The existing studies analyze the design of RE policies in the absences of carbon prices. We add in two different ways: On the one hand, we theoretically derive how optimal feed-in tariffs and premiums need to be adjusted in the presence of a carbon price. On the other hand, we quantify the necessary adjustments for the case of the UK. We show that the differentiation of optimal RE subsidies due to different production profiles and changing marginal external benefits is small, but the necessary adjustment of RE premiums to reflect the carbon value in the electricity market price is substantial.

The second strand of literature assesses the impacts of either carbon prices or RE promotion on fossil generation and emissions. For example, Cullen (2013), Kaffine et al. (2013), Novan (2015), and Abrell et al. (2019a) analyze the environmental effectiveness of renewable support. However, these studies do not take into account the variation of the emission offset of $\mathrm{RE}$ production due to changes in relative fuel and carbon prices. Cullen \& Mansur (2017) use the variation in gas prices to infer the impacts of a carbon price on fossil generation, but do not assess the environmental effectiveness of RE sources. We follow the approach of Cullen \& Mansur (2017) using fuel price variations to identify the changes in the merit-order curve, and contribute to the existing studies by looking at the interaction of both policies, i. e., carbon pricing and RES.

Third, there is a growing literature on the interaction of climate policies in the power sector. Most studies focus on the interaction of RE policies with emission trading systems through their impacts on carbon prices (see, e.g., Abrell \& Weigt, 2008; Böhringer \& Rosendahl, 2010; Gonzalez, 2007; Böhringer \& Behrens, 2015). The general argument is that RES schemes lead to a reduced demand for emission allowances and therefore a decrease of the carbon price, which in turn favors dirty technologies such as coal. To the best of our knowledge, there are only three studies analyzing the impact of RE generation on emissions for different fuel price regimes: Weigt et al. (2012) use a simulation model of the German power market to analyze the interaction of carbon prices and the environmental effectiveness of RE promotion. Holladay \& LaRiviere (2017) look at the interaction of relative fuel prices and RE-induced abatement in the US power sector. They exploit the variation in gas prices during the shale 
gas boom to distinguish between two fuel price regimes. ${ }^{1}$ Fell \& Kaffine (2018) analyze the impact of lower gas prices and higher wind generation on coal generation and emissions in the US electricity market. They look at both impacts individually as well as their interaction. They find that lower gas prices lead to a substantial increase of wind-induced abatement. The first part of our analysis on the impact of relative fuel prices on RE-induced abatement is similar to these studies. In addition, we contribute by using and comparing two different methods, i. e., numerical simulation and empirical estimation, and by going one step further and additionally add on the optimal design of RES policies in the presence of carbon prices.

The remainder of this paper proceeds as follows. In the next section we derive optimal RE subsidies in the presence of carbon prices and how these subsidies need to account for changes in carbon prices. In Section 3 we present the background on RES and carbon pricing in the UK followed by a description of our estimation strategy, numerical modeling approach, and data used. Section 4 shows the empirical results how optimal RES needs to be adjusted for fuel switching. Section 5 analyzes the impact of varying carbon prices in RE promotion based on the numerical approach. Section 6 summarizes and discusses our results and finally concludes.

\section{Carbon Prices and Renewable Energy Promotion}

In this section, we first explain the impact of introducing a carbon price on the emission offset of RE production. Afterwards, we examine the implication of introducing a carbon price on the optimal promotion of RE generation in form of a production subsidy.

\subsection{The Interaction of Carbon Pricing and the Emission Offsets of Renewable Energies}

The impact of RE production on emissions in the power sector depends on two major factors. First, production profiles determine at which point in time the respective RE source replaces fossil production. Second, the emission rate of the marginal power plant, the marginal emission rate $(M E R)$, determines the decrease of carbon emissions induced by RE production in a particular hour. The production profile depends on the availability of natural resources, and thus is independent of carbon prices. A carbon price does, however, impact the $M E R$ by altering the marginal cost of power plants, and thus the ordering of fossil power plants along the supply curve.

Following Callaway et al. (2018), we express the production profile of natural resource $r$ as the share of total production realized in period $t, \omega_{r t}$, which sums up to one over the whole time horizon from $t=0$ to $T\left(\sum_{t=0}^{T} \omega_{r t}=1\right){ }^{2}$ Given the production profile, the average marginal emission offset, $\delta_{r}^{E}$, i. e., the amount

\footnotetext{
${ }^{1}$ Holladay \& Soloway (2016) estimate the impact of the fuel price spread on fossil generation and emissions. While we use a similar method, we differ with respect to the research question: They focus on the direct effect of fuel prices on generation and emissions, while we are interested in the indirect impact of relative fuel prices via their impact on RE.

${ }^{2} \omega_{r t}$ expresses how many percent of total production is realized in hour $t$. As an example, if resource $r$ produces $1 \mathrm{GWh}$ in period $t$ and $1000 \mathrm{GWh}$ over the whole time horizon, $\omega_{r t}$ would be $0.1 \%$.
} 
of emissions on average avoided by one unit of production of the respective RE source, is given as:

$$
\delta_{r}^{E}:=\sum_{t=1}^{T} \omega_{r t} \cdot M E R_{t} .
$$

Carbon prices can affect the marginal emission offset in two ways: First, they alter the relative cost - and possibly the order - of power plants in the meritorder curve. As the supply curve together with demand for electricity determines the marginal plant, carbon prices can alter the MER. Second, whereas carbon prices do not affect the production profile of the RE source itself, they affect the correlation of RE generation with marginal emission rates.

IMPACT OF CARBON PRICE ON THE MER - At first glance, one might expect that a carbon price leads to a decrease of the average $M E R$, as it drives carbon intense power plants out of the market. Yet, this has not to be the case. Consider a system in which demand in all hours is constantly at the high level in Figure 1. The marginal generator then switches from a gas to a coal plant in all hours, leading to an increase in the average $M E R$. The impact of a carbon price on the average $M E R$ is thus a priori unclear. ${ }^{3}$

Figure 1 illustrates the dependence of the $M E R$ on the introduction of a carbon price and demand. Panel (a) depicts a situation without a carbon price. In this cheap coal situation, carbon intense coal plants are dispatched before gas-fired plants. The $M E R$ is thus decreasing in demand. Introducing a carbon price alters relative cost of coal and gas power plants. Coal generation with low operating cost but high emissions is then driven to the right of the supply curve. In the extreme, a full fuel switch takes places and all gas plants are dispatched before coal-fired plants as shown in Panel (b). ${ }^{4}$ The $M E R$ then increases in demand.

IMPACT OF CARBON PRICE ON CORRELATION OF MER AND RE PROFILE-The second part that defines the emissions impact of $\mathrm{RE}$ is the correlation of the $M E R$ with the RE production profile. This profile effect differs across RE resources. Figure 2 depicts the mean hourly production of wind and solar power together with mean demand. It becomes evident, that solar production is correlated with high demand hours whereas wind production seems to be only slightly positively correlated with demand. ${ }^{5}$ The change from the cheap coal to fuel switch regime (induced by a carbon price) leads to a higher $M E R$ rate in high demand hours. As solar production coincides with these high demand hours, the fuel switch increases the covariance effect of emission offset for solar power. For wind power, the effect is ambiguous as wind production occurs during low and high demand hours.

In summary, it is a priori unclear whether increasing carbon prices lead to a higher or lower emission offset of RE production. In the case of solar, we expect that a carbon price induces higher abatement, as carbon intensive

\footnotetext{
${ }^{3}$ Note, however, that this does not imply that the carbon price does not decrease emissions. In contrast, as in the example all gas plants are dispatched first, total emissions decrease but the MER increases.

${ }^{4}$ The carbon price of $70 € / \mathrm{tCO}_{2}$ has never been observed in the data but is chosen here for illustrative purpose to achieve two merit-order curves completely separated by technology.

${ }^{5}$ Over our sample period the correlation between demand and solar (wind) is $36 \%(10 \%)$.
} 
Figure 1. Merit-order curves for cheap coal and fuel switch situation

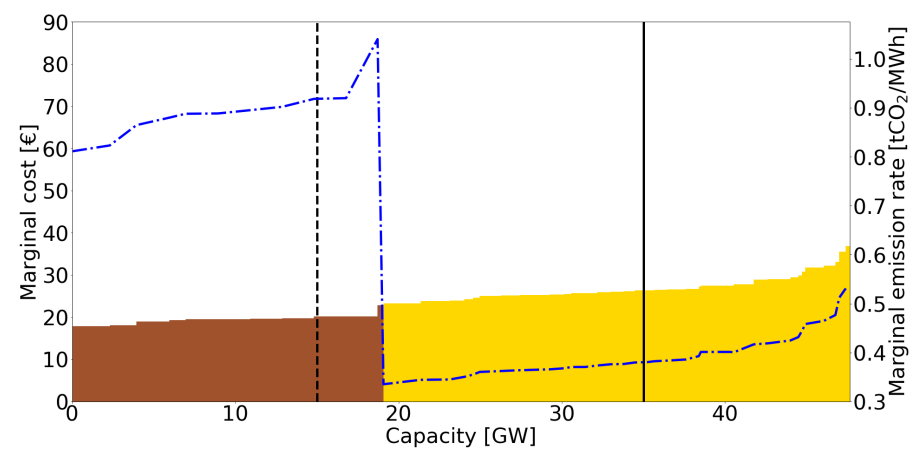

(a) Cheap coal

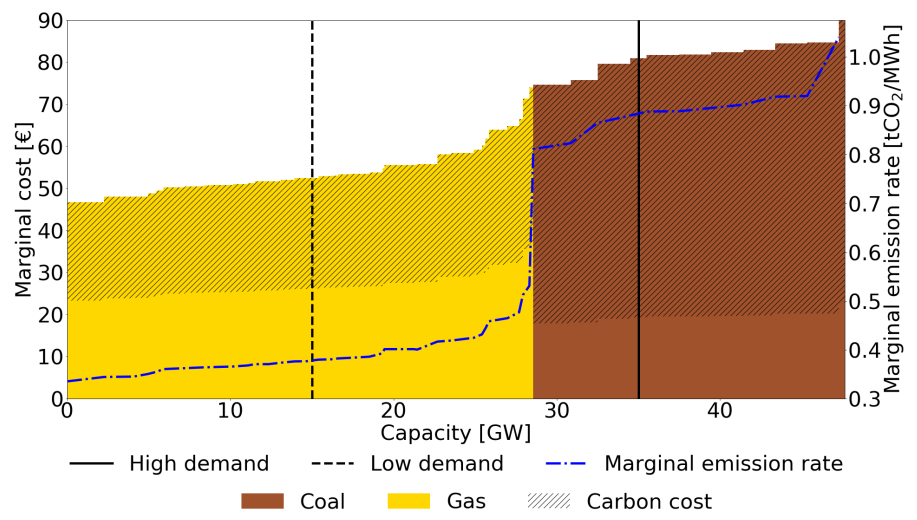

(b) Fuel Switch

Notes: Shown are merit-order curves for the UK electricity system based on fuel prices on 30 June 2016. The coal (gas) price was $7.5(13.9) € / \mathrm{MWh}_{t h}$. For sources of power plant capacities and heat efficiencies see Appendix B. The resulting marginal costs are measured on the left axis. Demand (black lines) refers to demand net of production of base load technologies. The marginal emission rate (blue line) is measured on the right axis. Cheap coal in Panel (a) refers to a situation with a zero carbon price. In the Fuel switch situation in Panel (b) a carbon price of $70 € / \mathrm{tCO}_{2}$ leads to a completly separated merit-order curve in which gas plants are dispatched first.

coal production is more likely to be marginal in high demand hours when solar generation peaks. In the case of wind, which has no pronounced daily production profile, the impact of a carbon tax can go in both directions.

\subsection{Implications for Optimal Renewable Promotion}

Optimal RE promotion equates the average marginal income of RE producers with the average marginal economic value (MEV) (see Callaway et al., 2018; Abrell et al., 2019c). ${ }^{6}$

\footnotetext{
${ }^{6}$ Once the RE facilities are installed the production profile is exogenously determined by resource availability and cannot be changed. Thus, the income stream is determined and aver-
} 
Figure 2. RE production and demand profiles

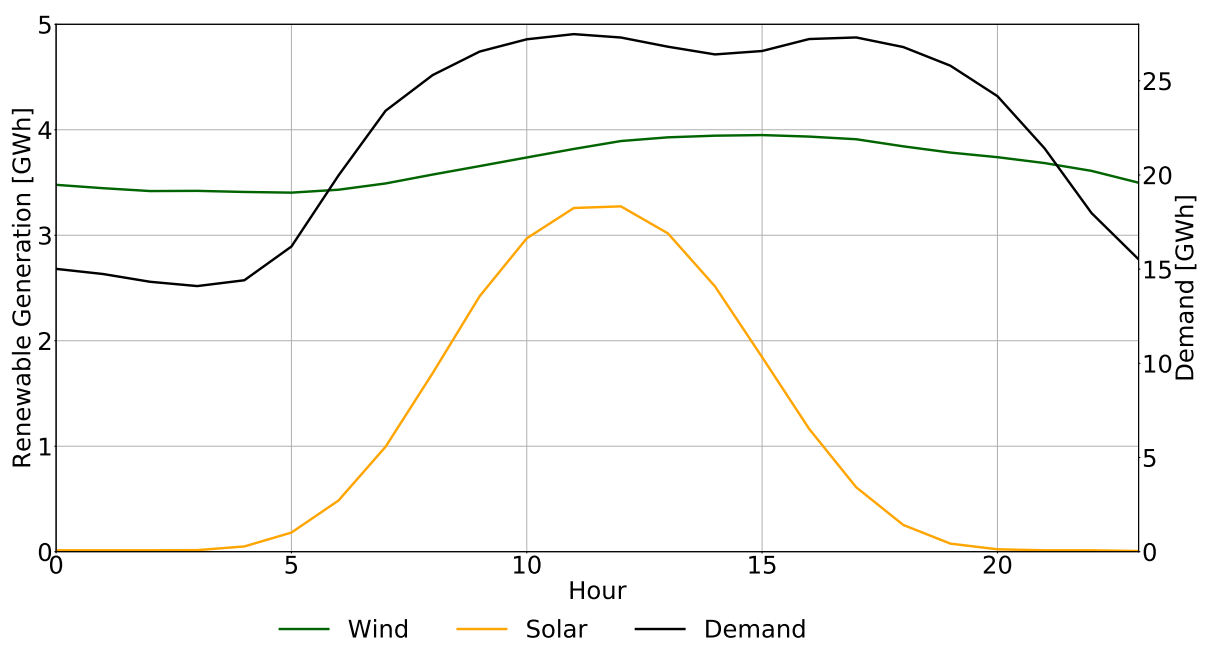

Notes: Shown are hourly mean wind (green) and solar (orange) production (measured on the left axis) and hourly mean demand (black, measured on the right axis) for our sample period from 2015 to 2016. See Appendix B for data sources.

We consider two major forms of RE promotion in the form of production subsidies which differ in terms of their marginal income. First, feed-in tariffs grant a production subsidy to RE sources, $s_{r}^{F I T}$, but these sources do not receive the market income. ${ }^{7}$ Second, RE premiums grant a production subsidy, $s_{r}^{\text {Premium }}$ on top of the market income.

MARGINAL ECONOMIC VALUE—The MEV of RE sources includes two main components: Cost avoided as conventional plants are replaced and the marginal external benefit (MEB).

We consider the cost avoided as the operating cost $c_{t}$ net of carbon cost. Callaway et al. (2018) also include the value of avoided capacity cost. This is relevant for $\mathrm{RE}$ sources active in peak hours, as these might avoid installing additional peak-load capacity. However, during our period of analysis, the UK established a capacity market that excluded RE sources. We thus assume that RE sources do not replace conventional capacity. ${ }^{8}$

We assume the MEB to be equal to the social cost of carbon emissions avoided: $M E B:=S C C \cdot \delta_{r}^{E}=S C C \sum_{t} \omega_{r t} M E R_{t}$, i. e., we evaluate the carbon emissions avoided at the social cost of carbon (SCC). ${ }^{9}$

age marginal values provide the incentive to invest into the facilities to provide an additional unit of RE production.

${ }^{7}$ One possibility is that the regulator or transmission system operator brings the RE production to the market and receives the market income that is used to partially refinance subsidy expenses.

${ }^{8}$ Including a capacity value would likely increase subsidies for solar power, as it is mostly active in peak load hours and thus likely to avoid larger amounts of capacity.

${ }^{9}$ We concentrate on the marginal external benefit in terms of avoided carbon emissions which are the major emission component avoided. Also, we abstract from learning externalities 
FEED-IN TARIFF_ - Under a feed-in system, RE producers receive only the production subsidy and no further income. ${ }^{10}$ The average marginal income therefore equals the feed-in rate $s_{r}^{F I T}$ and the optimal feed-in rate becomes:

$$
s_{r}^{* F I T}=M E V_{r}=\underbrace{\sum_{t} \omega_{r t} c_{t}}_{\text {Avoided cost }}+\underbrace{S C C \cdot \delta_{r}^{E}}_{M E B_{r}} .
$$

In each period, operating cost net of the cost for carbon emissions of the marginal generator, $c_{t}$ determine cost avoided. The $M E B$ equals the average marginal emission offset evaluated at the social cost of carbon.

To see how the optimal feed-in $s_{r}^{* F I T}$ changes with the introduction of a carbon price $\tau$, we differentiate equation (2) with respect to the carbon price.

$$
\frac{\partial s_{r}^{* F I T}}{\partial \tau}=\sum_{t} \omega_{r t} \frac{\partial c_{t}}{\partial \tau}+S C C \frac{\partial \delta_{r}^{E}}{\partial \tau}
$$

Introducing a carbon price, the optimal feed-in needs to be adjusted to reflect the change in the avoided net-of-carbon cost (first part) and the change in the $M E B$ (second part). Both, the change in cost avoided and the change in MEB, depend on the ordering of technologies in the merit-order curve and, thus, the correlation of the RE source with the marginal generator. In case the tax does not lead to a re-ordering of the merit-order curve (no fuel switch), the feed-in remains constant. In contrary, if the introduction of the tax leads to a fuel switch, it is not a priori clear, whether the optimal feed-in needs to be higher or lower. In the case of solar power with a high correlation with demand, we observe two contradicting effects: First, the feed-in is likely to increase as the carbon offset becomes larger. Second, the feed-in is likely to decrease as at least operating-cost avoided decrease. In other words, solar now replaces more cheap but dirty coal, and less expensive but cleaner gas generation. In the case of wind, both effects can go in both directions as wind generation does not show a pronounced correlation with demand. Yet, again the two effects need to be contradicting, as high costs are correlated with low emissions and vice versa. Which effect dominates needs to be determined empirically as it depends on the context.

PREMIUM - Under a premium system, RE sources receive the production subsidy on top of the market price for electricity, $P_{t}$. In the absence of competitive distortions, the electricity price equals the sum of operating and carbon cost of the marginal generator: $P_{t}=c_{t}+\tau \cdot M E R_{t} \cdot{ }^{11}$ The optimal RE premium, $s_{r}^{* \text { Premium }}$, is set such that the $M E V$ equals the average marginal income of the

that are another major reason to subsidize RE production. Including these additional externa benefits would increase the respective subsidy.

${ }^{10}$ Lamp \& Samano (2020) include the value received from ancilliary service markets. Estimating this value for PV production in Germany, they however show that this value is likely to be small. We therefore neglect ancillary service income also because RE production was not allowed to participate in the UK balancing mechanism.

${ }^{11}$ To introduce imperfect competition, we would need to include a markup over marginal cost. However, for the UK power system, the "Competition and Markets Authority" (CMA, 2016) did not find evidence for anti-competitive behavior in the wholesale electricity market. 
RE producer consisting of the market income and the premium:

$$
\begin{gathered}
\sum_{t} \omega_{r t} c_{t}+S C C \cdot \delta_{r}^{E} \stackrel{!}{=} \sum_{t} \omega_{r t} P_{t}+s_{r}^{* \text { Premium }} \\
\Longrightarrow s_{r}^{* \text { Premium }}=(S C C-\tau) \delta_{r}^{E}
\end{gathered}
$$

As a carbon price leads to the (partial) reflection of external costs through the market price, the optimal premium only pays a subsidy equal to the external cost not addressed by the carbon price. This is reflected by the difference between the social cost of carbon (SCC) and the carbon tax $(\tau)$. As long as the carbon price is sub-optimally low $(\tau<S C C)$, the premium is positive. If carbon is optimally priced at the SCC, there is no room for further carbon income, thus, the premium becomes zero. In the extreme that carbon prices exceed the SCC, the optimal premium becomes negative, i. e., RE production would need to be taxed to avoid excess market entry by RE.

A change in $\tau$ requires adjusting the optimal premium in two ways:

$$
\frac{\partial s_{r}^{* \text { Premium }}}{\partial \tau}=\underbrace{-\delta_{r}^{E}}_{\text {Carbon rent effect }}+\underbrace{(S C C-\tau) \frac{\partial \delta_{r}^{E}}{\partial \tau}}_{\text {Change MEB }}
$$

First, increasing $\tau$ leads to an increased reflection of the external cost in the market price. Thus, the optimal premium needs to be decreased (first term). The extend of this effect depends on the marginal emission offset $\delta_{r}^{E}$. Second, if the tax induces a fuel switch, $\delta_{r}^{E}$ itself changes (second term). The sign and extend of the adjustments due to a change in the environmental effectiveness of the RE source is again ambiguous. On the one hand, it depends on the sign and magnitude of the change of $\delta_{r}^{E}$. As explained above, we expect the change in $\delta_{r}^{E}$ to be positive for solar and positive or negative for wind. On the other hand, it depends on the level of the carbon price: When carbon prices are small, the second term is high and has the same sign as the change in $\delta_{r}^{E}$, i.e., a higher emission offset implies a higher premium. With increasing carbon prices, this adjustment motive becomes less important. When the carbon tax is higher than the social cost of carbon, the sign of the second term reverses.

COMPARING FEED-IN TARIFF AND PREMIUM - The major difference between the optimal feed-in and the optimal premium is the adjustment for the external cost reflected in the market prices. If an increase in $\tau$ does not trigger a fuel switch, the feed-in remains constant. In contrast, the premium needs to be decreased to account for the carbon rent received through the market price and might even become negative once the carbon price exceeds the social cost of carbon.

On contrary, if a fuel switch occurs, both feed-in and premium, need to be adjusted. If the environmental effectiveness increases - as we expect for solar power - the marginal external benefit increases, which generally has an increasing effect on the optimal subsidy. Yet, for the premium this effect decreases in the tax level. For the feed-in, the decrease of avoided operating cost weakens the effect of an increasing marginal emission offset. 


\section{Empirical Framework}

For our empirical applications we use data from the UK electricity sector in the years 2015 and 2016. We choose the UK due to three major characteristics. First, the UK had a diverse portfolio of installed capacities, including coal and gas-fired power plants. This capacity mix allows for fuel switching as short-term response to carbon prices. Second, the UK implemented extensive renewable energy support (RES) schemes to promote solar and wind energy. Third, the UK imposed a carbon tax on top of the European Emission Trading System (EU ETS). Together with the low natural gas prices in 2016, this price induced a fuel switch away from coal towards gas generation. It is important to note, that the carbon tax stayed relatively constant over the whole sample period, but due to a large variation in gas prices, we observe periods with and without fuel switch. In concentrating on a fuel switch under constant carbon prices, we estimate the optimal adjustment of feed-in tariffs and RE premiums due to a re-ordering of the merit-order curve. Moreover, we estimate the carbon value embedded in the market prices and how it changes due to changes in the meritorder. However, as we do not observe a considerable variation in the carbon price (see Table 3), we are not able to estimate the impact of varying carbon prices on optimal subsidies. To illustrate the effect of carbon prices on optimal $\mathrm{RE}$ promotion, we additionally use a numerical model of the UK power market and simulate optimal RE promotion under varying carbon prices.

We proceed by reviewing climate regulations in the UK power sector followed by explaining our econometric approach and simulation model. Finally, we present the underlying data sources.

\subsection{Renewable Support and Carbon Pricing policies in the UK}

The European Renewable Energy Directive from the year 2009 (Directive 2009/29/EC) set the RE target for the UK to $15 \%$ until $2020 .{ }^{12}$ To reach this target, the UK implemented a variety of extensive support schemes to promote RE generation in the power sector (see Appendix A for more detailed information). Indeed, the large support for RE has led to a significant share of wind and solar generation in 2015/2016 as shown in Table 1.

Next to RES policies, the UK power sector is subject to two carbon pricing systems: The European Emission Trading System (EU ETS) and the UK Carbon Price Support (CPS), an additional carbon tax on emissions stemming from the electricity sector. The CPS complements the price for European Emission Allowances (EUA) in order to reach a minimum carbon price, the so called Carbon Price Floor (CPF). It was announced in 2011 and introduced in 2013, starting at a level of $4.4 € / \mathrm{tCO}_{2}$. Since the second quarter of 2015 the CPS has been capped at a level of $18 \mathrm{GBP} / \mathrm{tCO}_{2}$ (about $\left.22 € / \mathrm{tCO}_{2}\right) \cdot{ }^{13}$ Due to the introduction of the CPS, electricity generators in the UK face a much higher

\footnotetext{
${ }^{12}$ Although this target also includes heat and transport, the electricity sector is most important to reach the overall target. In 2015/16 the UK exceeded the interim target of $7.5 \%$ with a RE share of $8.5 \%$. The RE share in the electricity sector was around $23 \%$ at this time (DUKES, 2017).

${ }^{13}$ We convert the CPS rate to Euro using ECB exchange rates (ECB, 2017). The variation observed in Table 1 stems from this pound-to-euro conversion.
} 
TABLE 1. Quarterly RE generation, fuel and carbon prices, and carbon emissions

\begin{tabular}{|c|c|c|c|c|c|c|c|c|}
\hline & \multicolumn{4}{|c|}{2015} & \multicolumn{4}{|c|}{2016} \\
\hline & Q1 & Q2 & Q3 & Q4 & Q1 & Q2 & Q3 & Q4 \\
\hline \multicolumn{9}{|c|}{ Generation [TWh] } \\
\hline Wind & $\begin{array}{l}10.11 \\
12.7 \%\end{array}$ & $\begin{array}{c}6.69 \\
10.3 \%\end{array}$ & $\begin{array}{l}5.84 \\
9.3 \%\end{array}$ & $\begin{array}{c}9.81 \\
13.6 \%\end{array}$ & $\begin{array}{c}8.81 \\
11.7 \%\end{array}$ & $\begin{array}{l}5.95 \\
9.3 \%\end{array}$ & $\begin{array}{c}6.63 \\
10.7 \%\end{array}$ & $\begin{array}{c}10.49 \\
13.2 \%\end{array}$ \\
\hline Solar & $\begin{array}{l}1.06 \\
1.3 \%\end{array}$ & $\begin{array}{c}3.58 \\
5.5 \%\end{array}$ & $\begin{array}{l}2.93 \\
4.7 \%\end{array}$ & $\begin{array}{c}0.85 \\
1.2 \%\end{array}$ & $\begin{array}{l}1.42 \\
1.9 \%\end{array}$ & $\begin{array}{c}3.44 \\
5.4 \%\end{array}$ & $\begin{array}{c}3.43 \\
5.5 \%\end{array}$ & $\begin{array}{c}1.51 \\
1.9 \%\end{array}$ \\
\hline Coal & $\begin{array}{l}28.70 \\
36.0 \%\end{array}$ & $\begin{array}{r}16.60 \\
25.5 \%\end{array}$ & $\begin{array}{l}12.63 \\
20.1 \%\end{array}$ & $\begin{array}{c}16.53 \\
22.8 \%\end{array}$ & $\begin{array}{c}13.69 \\
18.2 \%\end{array}$ & $\begin{array}{l}4.05 \\
6.4 \%\end{array}$ & $\begin{array}{l}2.28 \\
3.7 \%\end{array}$ & $\begin{array}{c}7.96 \\
10.1 \%\end{array}$ \\
\hline Gas & $\begin{array}{c}19.65 \\
24.7 \%\end{array}$ & $\begin{array}{c}19.63 \\
30.1 \%\end{array}$ & $\begin{array}{l}22.57 \\
36.0 \%\end{array}$ & $\begin{array}{c}22.50 \\
31.1 \%\end{array}$ & $\begin{array}{r}29.95 \\
39.7 \%\end{array}$ & $\begin{array}{c}30.58 \\
48.0 \%\end{array}$ & $\begin{array}{c}29.03 \\
47.0 \%\end{array}$ & $\begin{array}{c}37.69 \\
47.6 \%\end{array}$ \\
\hline \multicolumn{9}{|c|}{ Fuel Prices [€/MWh thermal energy] } \\
\hline Coal & $\begin{array}{c}8.16 \\
(0.38)\end{array}$ & $\begin{array}{c}8.02 \\
(0.24)\end{array}$ & $\begin{array}{c}7.63 \\
(0.36)\end{array}$ & $\begin{array}{c}7.02 \\
(0.38)\end{array}$ & $\begin{array}{c}6.20 \\
(0.23)\end{array}$ & $\begin{array}{c}6.46 \\
(0.44)\end{array}$ & $\begin{array}{c}8.08 \\
(0.29)\end{array}$ & $\begin{array}{l}11.71 \\
(0.93)\end{array}$ \\
\hline Gas & $\begin{array}{l}22.02 \\
(1.40)\end{array}$ & $\begin{array}{l}21.19 \\
(0.94)\end{array}$ & $\begin{array}{l}19.74 \\
(1.14)\end{array}$ & $\begin{array}{l}17.25 \\
(1.40)\end{array}$ & $\begin{array}{l}13.51 \\
(0.91)\end{array}$ & $\begin{array}{l}13.54 \\
(1.19)\end{array}$ & $\begin{array}{l}12.47 \\
(1.65)\end{array}$ & $\begin{array}{l}17.98 \\
(1.59)\end{array}$ \\
\hline \multicolumn{9}{|c|}{ Carbon Prices $\left[€ / \mathrm{tCO}_{2}\right]$} \\
\hline EUA & $\begin{array}{c}7.03 \\
(0.32)\end{array}$ & $\begin{array}{c}7.37 \\
(0.24)\end{array}$ & $\begin{array}{c}7.97 \\
(0.25)\end{array}$ & $\begin{array}{c}8.36 \\
(0.21)\end{array}$ & $\begin{array}{c}5.66 \\
(0.99)\end{array}$ & $\begin{array}{c}5.74 \\
(0.41)\end{array}$ & $\begin{array}{c}4.55 \\
(0.27)\end{array}$ & $\begin{array}{c}5.52 \\
(0.62)\end{array}$ \\
\hline CPS & $\begin{array}{l}12.85 \\
(0.35)\end{array}$ & $\begin{array}{l}25.06 \\
(0.37)\end{array}$ & $\begin{array}{l}25.20 \\
(0.45)\end{array}$ & $\begin{array}{l}25.05 \\
(0.46)\end{array}$ & $\begin{array}{l}23.49 \\
(0.47)\end{array}$ & $\begin{array}{l}22.89 \\
(0.45)\end{array}$ & $\begin{array}{l}21.19 \\
(0.25)\end{array}$ & $\begin{array}{l}20.74 \\
(0.55)\end{array}$ \\
\hline Carbon Price & 19.88 & 32.42 & 33.17 & 33.41 & 29.16 & 28.63 & 25.74 & 26.25 \\
\hline \multicolumn{9}{|c|}{ Carbon emissions $[\mathrm{Mt}]$} \\
\hline Total & 30.64 & 20.77 & 19.36 & 22.86 & 23.37 & 15.03 & 12.55 & 20.22 \\
\hline
\end{tabular}

Notes: Standard deviations in parentheses. Precentages indicate share in total generation. See Appendix B for data sources and construction.

carbon price compared to the rest of Europe confronted only with the EUA price.

Figure 3 shows the coal-to-gas price ratio with and without carbon prices, as well as yearly coal and gas generation. As expected, in years when coal generation is cheaper, there is more coal production. With an increasing price ratio, more gas production is observed. The horizontal line denotes a coal-to-gas price ratio of 0.74 at which marginal cost for coal and gas plants are on average equal. When the ratio is larger than 0.74 , gas generation is on average cheaper than coal generation. ${ }^{14}$ It becomes evident that except for a short period in September 2016, carbon prices have been crucial to exceed the threshold value of 0.74 to achieve an average fuel switch. Yet, it is also important to note, that the carbon price was relatively stable over the whole sample period. It was much more the gas prices that decreased in 2016, and thus - in combination with the high carbon prices - allowed for a fuel switch.

\subsection{Model of the UK Power Market}

In the UK power market, power plants bid supply into the wholesale market. Assuming perfect competition, ${ }^{15}$ power plant $i$ bids the capacity available in

\footnotetext{
${ }^{14}$ See Section 3.3 for more details on the calculation of the fuel price ratio.

${ }^{15}$ CMA (2016) did not find evidence for anti-competitive behavior in the wholesale electricity market.
} 
FiguRE 3. Fossil generation and fuel price ratios

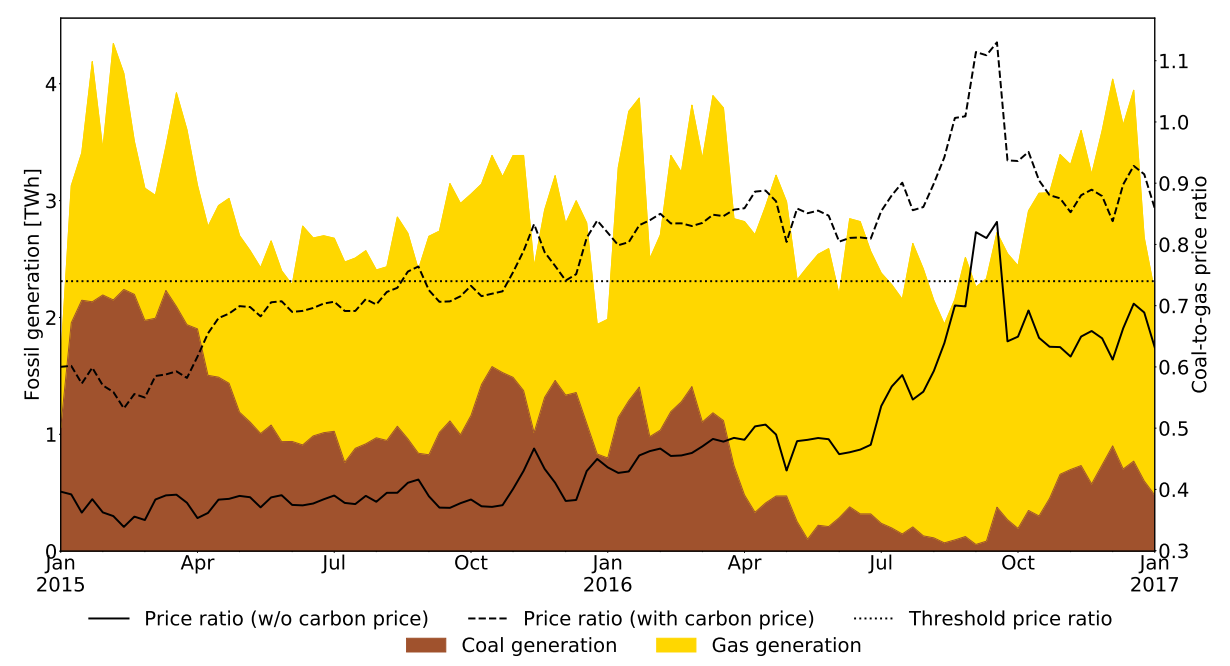

Notes: Generation of coal and gas-fired plants is measured on the left axis. The right axis measures the coal-to-gas price ratio with and without carbon prices. For data sources and construction see Appendix B.

hour $t, k_{i t}$ at marginal generation costs, $c_{i t}$. The latter depend on various factors:

$$
c_{i t}=c_{i t}\left(\eta_{i t}, p_{i}^{f}, p^{C O_{2}}, q_{i t}, q_{i(t-1)}\right)
$$

The heat efficiency $\eta_{i t}$ indicates the conversion efficiency, i. e., how much fuel is needed to produce a unit of electricity. It is time-depended, as it depends on ambient temperature. $p_{i}^{f}$ and $p^{C_{2}}$ denote the fuel and carbon price faced by plant $i$. Due to ramping constraints and start-up costs, power plant costs might be dynamic (Mansur, 2008; Reguant, 2014). Marginal cost therefore depend on the plants' contemporaneous $\left(q_{i t}\right)$ and past generation $q_{i(t-1)}$.

Production from wind and solar plants, $w_{t}$ and $s_{t}$ have near-zero marginal cost. Thus RE generation is always used before dispatching conventional plants. To meet hourly demand $d_{t}$ net of renewable generation and provided the bids, i. e., $k_{i t}$ and $c_{i t}$, of conventional power plant $i$, the system operator chooses generation of each plant $q_{i t}$ to minimize total system cost:

$$
\begin{aligned}
\min _{q_{i t} \geq 0} \sum_{i, t} c_{i t}\left(\eta_{i t}, p_{i}^{f}, p^{C O_{2}}, q_{i(t-1)}\right) q_{i t} \\
\sum_{i} q_{i t}=d_{t}-w_{t}-s_{t} \\
k_{i t} \geq q_{i t}
\end{aligned}
$$

$\forall t$

$\forall i, t$

Solving (7) leads to setting up the merit-order curve for each hour (see Figure 1 ). The result determines the generation of each power plant as a function of demand, renewable production, own as well as all other plants' cost characteristics 
and available capacities:

$$
q_{i t}=q_{i t}\left(d_{t}, w_{t}, s_{t}, \eta_{i t}, \eta_{-i t}, p_{i}^{f}, p_{-i}^{f}, p^{C O_{2}}, q_{i(t-1)}, q_{-i(t-1)}, k_{i(t-1)}, k_{-i(t-1)}\right)
$$

\subsection{Estimation Approach}

In the econometric approach, we are interested in estimating how a fuel switch affects the abatement impact of wind and solar power. To this end, we distinguish between two regimes (see Figure 3): In the cheap coal regime, coal generation is on average cheaper than gas. In the fuel switch regime, gasfired plants are on average cheaper than coal-fired ones. However, as we do not observe emissions directly, we first estimate the replacement of coal and gas generation induced by wind and solar generation. We then evaluate this replacement using average heat efficiencies and emission factors to determine emissions avoided.

We estimate the replacement of conventional generation on the technology level, i. e., $i \in\{$ Coal, Gas $\}$, using a reduced form model based on equation (8):

$$
\begin{aligned}
q_{i t}= & \sum_{\tilde{\phi}}\left(\alpha_{\tilde{\phi}}+\beta_{1 w i \tilde{\phi}} w_{t}+\beta_{1 s i \tilde{\phi}} s_{t}+\beta_{2 i \tilde{\phi}} d_{t}+\beta_{3 i \tilde{\phi}} \phi_{t}+\right. \\
& \left.\beta_{4 i \tilde{\phi}} t e m p_{t}+\boldsymbol{\beta}_{\mathbf{5 i}} \boldsymbol{k}_{\boldsymbol{t}}+\boldsymbol{\gamma}_{\boldsymbol{i}} \boldsymbol{V}_{\boldsymbol{t}}\right) I_{t \tilde{\phi}}+\boldsymbol{\delta}_{\boldsymbol{i}} \boldsymbol{D}_{\boldsymbol{t}}+\epsilon_{i t},
\end{aligned}
$$

where $\beta_{1 w i \tilde{\phi}}$ and $\beta_{1 s i \tilde{\phi}}$ are our main coefficients of interest measuring the replacement effect of wind and solar generation for the two fossil technologies and regimes. Demand is measured as final demand net of base-load generation (mainly hydro and nuclear power in the case of the UK) and imports/exports. Generation depends on both, own and other plants costs and available capacity, we thus include the vector of hourly available capacities $\boldsymbol{k}_{\boldsymbol{t}}$ and the carbon price inclusive coal-to-gas price ratio $\phi$ :

$$
\phi_{t}:=\frac{p^{\text {coal }}+\theta^{\text {coal }} p^{c a r b}}{p^{\text {gas }}+\theta^{\text {gas }} p^{c a r b}},
$$

where $p^{\text {coal }}$ and $p^{g a s}$ are fuel prices, $p^{\text {carb }}$ is the carbon price consisting of EUA and CPS prices, and $\theta_{i}^{f u e l}$ is the fuel-specific emission factor per MWh of thermal energy. ${ }^{16}$ As we do not observe the time variation of heat efficiencies, we include temperature (temp) as an indicator. To control for start-up and ramping costs as well as dynamic constraints, we include lagged terms of coal and gas generation and all contemporaneous controls over the previous 12 hours, $V_{t}$.

Table 2 gives an overview of all variables included in the estimation. Data sources and construction are described in Appendix B.

The specification (9) allows coefficients to vary across the two different regimes: $\tilde{\phi} \in\{$ cheap coal, fuel switch $\}$. Given an average heat efficiency of 0.38 and 0.51 for coal and gas plants, respectively (see Appendix B), gas plants

${ }^{16} 0.34 \mathrm{tCO}_{2} / \mathrm{MWh}_{\mathrm{th}}$ for coal and $0.20 \mathrm{tCO}_{2} / \mathrm{MWh}_{\mathrm{th}}$ for gas (IPCC, 2006). 
TABLE 2. Variable description

\begin{tabular}{ll}
\hline \hline Variable & Description \\
\hline $\begin{array}{l}\text { Dependent variable } \\
q_{i t}\end{array}$ & Hourly generation of technology $i$ [MWh] \\
Contemporaneous variables & \\
$w_{t}$ & Hourly wind generation [MWh] \\
$s_{t}$ & Hourly solar generation [MWh] \\
$d_{t}$ & Hourly electricity demand [MWh] \\
$t e m p_{t}$ & Daily mean temperature [ ${ }^{\circ}$ ] \\
$\phi_{t}$ & Daily coal-to-gas price ratio \\
$k_{i t}$ & Hourly available capacity of technology $i$ [MW] \\
Lagged variables $\boldsymbol{V}_{\boldsymbol{t}}(\mathrm{T}=1, \ldots, 12)$ & \\
$q_{i(t-T)}$ and $q_{-i(t-T)}$ & \\
$w_{t-T}$ & Fossil generation lagged T hours \\
$s_{t-T}$ & Wind generation lagged T hours \\
$d_{t-T}$ & Solar generation lagged T hours \\
$t e m p_{t-T}$ & Demand lagged T hours \\
$\phi_{t-T}$ & Temperature lagged T hours \\
$k_{i(t-T)}$ and $k_{-i(t-T)}$ & Coal-to-gas price ratio lagged T hours \\
\hline \hline
\end{tabular}

Notes: The sample period covers the years 2015 and 2016.

are on average cheaper at a price ratio above $0.74 .^{17}$

ROBUSTNESS CHECKS - We analyze the robustness of our regression results along three dimensions. First, to control for unobserved variables which vary at an hourly or monthly level we allow for time fixed effects $\boldsymbol{D}_{\boldsymbol{t}}$ including a dummy for each hour of the day, for each month in the year, or each month of the sample year, respectively. In our preferred specification we do not include fixed effects.

Second, our threshold price ratio of 0.74 is based on average heat efficiencies and, thus, not a precise estimate of the ratio on average causing a fuel switch. We therefore analyze how robust the results are to altering the threshold value to 0.7 and 0.8 , respectively.

Third, the effects of RE on conventional generation might be non-linear and vary with the magnitude of demand and RE generation. Whereas our core specification is linear, we examine several non-linear specifications. First, we allow for quadratic and cubic terms of RE generation and demand. Second, we estimate two semi-parametric estimations to allow coefficients to alter by demand and $\mathrm{RE}$ level. In Appendix $\mathrm{C}$ we provide more details on each specification.

IDENTIFICATION AND EXOGENEITY ASSUMPTIONS-For the identification of our main coefficients of interest, $\beta_{1 \text { ri } \tilde{\phi}}$ and $\beta_{1 s i \tilde{\phi}}$, we rely on the exogenous hourly variation of wind and solar generation and demand. To consistently estimate the model, all explanatory variables need to be independent: In the shortrun, temperature and RE generation are exogenously determined by weather conditions. To ensure the exogeneity of demand, we need to rely on the assumption of inelastic electricity demand. This assumption seems to be plausible given the short-run nature of our approach. In the short-run demand is

${ }^{17}$ Gas plants are cheaper if $\frac{p^{\text {gas }}}{\eta_{\text {gas }}}<\frac{p^{\text {coal }}}{\eta_{\text {coal }}} \Longrightarrow \frac{p^{\text {coal }}}{p^{\text {gas }}}>\frac{\eta_{\text {gas }}}{\eta_{\text {coal }}}=\frac{0.38}{0.51}=0.74$. 
determined by economic activities and weather conditions and does not react to changes in the wholesale market price. Regarding the independence of fuel prices we argue that the UK market is too small to have a significant impact on international coal and natural gas prices. The CPS price is fixed at least two years in advance by the UK government, i. e., can be assumed to be exogenous in the short-run. Verified emissions caused by fuel combustion in the UK in the year 2015 accounted for only $6.6 \%$ of total emissions regulated under the EU ETS. ${ }^{18}$ Thus, we also assume that the EUA price is exogenous. Finally, hourly available capacities describe the maximal amount of energy that a plant is able to deliver in a given hour. Therefore, they are also exogenous in the short-run.

\subsection{Numerical Approach}

The numerical model models generation of each gas and coal power plant in the UK market. Following the approach outlined in Section 3.2, we need to specify the cost function to be able to implement a numerical model. Relying on the observed average heat efficiencies of each plant $\left(\eta_{i}\right)$ and the carbon price inclusive fuel price, $\tilde{p}_{i t}^{f}$, we parameterize the cost function of each plant as:

$$
\frac{\tilde{p}_{i t}^{f}}{\eta_{i}} q_{i t}+\left(c_{i}^{+}+c_{i}^{f+} \tilde{p}_{i t}^{f}\right) q_{i t}^{+}
$$

The first part expresses carbon cost inclusive operation cost determined by the carbon cost inclusive fuel price and the heat efficiency. The second part introduces additional cost caused by an increase in generation, so called ramping cost. $q_{i t}^{+}$denotes the increase in generation compared to the previous period. This ramping causes cost in two different forms. First $c_{i}^{+}$are cost caused by additional depreciation due to increased thermal stress. Second, $c_{i}^{f+}$ indicates additional fuel cost to increase generation and, thus, is evaluated at the current carbon inclusive fuel price.

With the definition of generation cost at hand, the numerical model becomes:

$$
\begin{aligned}
& \min _{q_{i t}, q_{i t}^{+} \geq 0} \sum_{i, t}\left[\frac{\tilde{p}_{i t}^{f}}{\eta_{i}} q_{i t}+\left(c_{i}^{+}+c_{i}^{f+} \tilde{p}_{i t}^{f}\right) q_{i t}^{+}\right] \\
& \sum_{i} q_{i t}=d_{t}-w_{t}-s_{t} \quad \forall t \\
& k_{i t} \geq q_{i t} \quad \forall i, t \\
& q_{i t}^{+} \geq q_{i t}-q_{i(t-1)} \quad \forall i, t
\end{aligned}
$$

The last equation together with the non-negativity constraint for ramping $q_{i t}^{+}$ implements the dynamic cost component due to ramping. ${ }^{19}$ The model is imple-

\footnotetext{
${ }^{18}$ Using the EU ETS viewer of the European Environmental Agency (https://www.eea. europa.eu/data-and-maps/dashboards/emissions-trading-viewer-1) for the year 2015, UK emissions from combustion of fossil fuels (including industry combustion) was $131 \mathrm{MtCO}_{2}$ whereas total emissions under the EU ETS summed up to $1978 \mathrm{MtCO}_{2}$.

${ }^{19}$ We do not include further dynamic cost components such start-up cost, minimum downtime, or minimum generation constraint. All of these components would require model formulations using binary decision variables, i.e., combinatorial optimization. Given that we model two years in hourly resolution, such approaches are computationally rather expensive.
} 
ment in the General Algebraic Modeling System (GAMS) software and solved as a linear problem using the CPLEX solver.

The program solves (12) for the optimal generation schedule of each power plant. The simulated hourly electricity price is provided as the shadow value of the market clearing equation (first constraint). We then derive the marginal plant as the plant with the minimum difference between the market price and the static fuel cost component. ${ }^{20}$ Knowing the marginal generator, we know the marginal emission rate and avoided cost in each hour. Using equations (2) and (4), we then derive the optimal feed-in and premium.

\subsection{Data}

Appendix B lists all data sources and describes the construction of each variable used in detail. For our estimation approach, we distinguish between two fuel price regimes. In the cheap coal regime, coal generation is on average cheaper than gas generation, in the fuel switch regime gas is cheaper. Table 3 compares hourly means and standard deviations of all variables across the two regimes.

By construction, the values of the carbon price inclusive coal-to-gas price ratio are lower in the cheap coal regime, and significantly higher in the fuel switch regime. Also the carbon price exclusive fuel price ratio is higher in the fuel switch case due to lower gas prices. However, it remains below the threshold level of 0.74 , indicating that - on average - coal generation was always cheaper than gas in the absence of a carbon price. Coal and carbon prices are nearly constant across the two regimes whereas gas prices are significantly lower in the fuel switch regime.

The other variables that show large differences in means between the two regimes are coal and gas generation: Coal generation is around twice as high in the cheap coal regime. Gas generation, on the other hand, is higher in the fuel switch regime. This difference is expected as the regime switch leads to a switch in the merit order, and therefore to a replacement of coal by gas generation.

Furthermore, coal capacity is clearly lower in the high price ratio regime. This is the case as the high price period almost exclusively comprises data of 2016, when several coal plants have been shut-down. It is therefore important to control for these changes in our estimation approach.

Finally, demand and RE generation as well as temperature are rather similar across the two regimes.

\section{The Impact of Fuel Switching on Renewable Energy Support}

\footnotetext{
Furthermore, we model power plants and not single power plant blocks. In an alternative approach, we included ramp-rate restrictions. However, these restrictions did not significantly alter the results. Thus, we exclude them here. The code implementing the numerical model, which is available on request, still allows for these restrictions.

${ }^{20}$ Due to the inclusion of ramping cost, the markup over marginal cost, i.e., the difference between the price and the static marginal cost, is not only the capacity rent but also includes the value of generation due to possibly avoided ramping cost. These avoided ramping cost are formally derived as the differences of the shadow value of the last constraint in (12) between subsequent periods. Thus, there are possibly multiple plants with a positive markup over pure static marginal cost.
} 
TABLE 3. Comparison of variables across fuel price regimes.

\begin{tabular}{|c|c|c|c|}
\hline & $\begin{array}{c}\text { cheap coal } \\
\phi<\hat{\phi}\end{array}$ & $\begin{array}{c}\text { fuel switch } \\
\phi \geq \hat{\phi}\end{array}$ & $\overline{\text { Difference }}$ \\
\hline Observation $[\#]$ & 6816 & 10726 & 3910 \\
\hline $\begin{array}{l}\text { Fuel price ratio } \\
\text { (incl. carbon price) }\end{array}$ & $\begin{array}{c}0.66 \\
(0.06)\end{array}$ & $\begin{array}{c}0.87 \\
(0.08)\end{array}$ & $\begin{array}{l}0.20 \\
0.00\end{array}$ \\
\hline $\begin{array}{l}\text { Fuel price ratio } \\
\text { (w/o carbon price) }\end{array}$ & $\begin{array}{c}0.38 \\
(0.01)\end{array}$ & $\begin{array}{c}0.54 \\
(0.11)\end{array}$ & $\begin{array}{l}0.16 \\
0.00\end{array}$ \\
\hline Coal price & $\begin{array}{c}7.87 \\
(0.47)\end{array}$ & $\begin{array}{c}7.94 \\
(2.10)\end{array}$ & $\begin{array}{c}0.06 \\
(0.01)\end{array}$ \\
\hline Gas price & $\begin{array}{l}20.92 \\
(1.48)\end{array}$ & $\begin{array}{l}14.84 \\
(2.55)\end{array}$ & $\begin{array}{l}-6.07 \\
(0.02)\end{array}$ \\
\hline Carbon price & $\begin{array}{l}28.71 \\
(6.04)\end{array}$ & $\begin{array}{l}28.53 \\
(2.81)\end{array}$ & $\begin{array}{l}-0.18 \\
(0.04)\end{array}$ \\
\hline Electricity price & $\begin{array}{l}41.41 \\
(9.77)\end{array}$ & $\begin{array}{c}39.84 \\
(29.04)\end{array}$ & $\begin{array}{l}-1.57 \\
(0.15)\end{array}$ \\
\hline Coal generation $[\mathrm{MWh}]$ & $\begin{array}{c}8533 \\
(3538)\end{array}$ & $\begin{array}{c}3926 \\
(3180)\end{array}$ & $\begin{array}{c}-4607 \\
(26)\end{array}$ \\
\hline Gas generation [MWh] & $\begin{array}{c}9439 \\
(4360)\end{array}$ & $\begin{array}{l}13213 \\
(4986)\end{array}$ & $\begin{array}{c}3774 \\
(36)\end{array}$ \\
\hline Demand [MWh] & $\begin{array}{l}22491 \\
(6795)\end{array}$ & $\begin{array}{l}21962 \\
(7084)\end{array}$ & $\begin{array}{l}-528 \\
(53)\end{array}$ \\
\hline Wind generation [MWh] & $\begin{array}{c}3405 \\
(2183)\end{array}$ & $\begin{array}{c}3833 \\
(2980)\end{array}$ & $\begin{array}{l}428 \\
(20)\end{array}$ \\
\hline Solar generation [MWh] & $\begin{array}{c}1114 \\
(1582)\end{array}$ & $\begin{array}{c}991 \\
(1556)\end{array}$ & $\begin{array}{l}-123 \\
(12)\end{array}$ \\
\hline Coal available capacity $[\mathrm{MW}]$ & $\begin{array}{l}12451 \\
(2626)\end{array}$ & $\begin{array}{c}9559 \\
(4040)\end{array}$ & $\begin{array}{c}-2892 \\
(25)\end{array}$ \\
\hline Gas available capacity [MW] & $\begin{array}{l}17419 \\
(1647)\end{array}$ & $\begin{array}{l}17732 \\
(1177)\end{array}$ & $\begin{array}{l}313 \\
(11)\end{array}$ \\
\hline Temperature & $\begin{array}{c}9.45 \\
(3.81)\end{array}$ & $\begin{array}{c}9.73 \\
(4.31)\end{array}$ & $\begin{array}{c}0.28 \\
(0.03)\end{array}$ \\
\hline
\end{tabular}

Notes: Values show hourly means with standard deviations in parentheses. The threshold value $\hat{\phi}=0.74$ marks the critical coal-to-gas price ratio above which gas generation is on average cheaper than coal generation. 


\subsection{Fuel Switch and Fossil Generation Displacement}

ESTIMATION RESULTS — Table 4 presents the estimation results from equation (9) per technology. As we allow the coefficients to vary between fuel price ratio regimes, there are two different coefficients for each variable. The left (right) two columns show results for coal (gas) generation depending on the respective regime.

All coefficients except those on the fuel price ratio and temperature are significant and show the expected signs: RE generation leads to a decrease of coal and gas generation. Generation of both technologies increase in demand but this effect is three times larger for gas than for coal generation. An increased availability of the own capacity leads to an increase in generation whereas the availability of the other technology's capacity decreases generation. Coefficients on the fuel price ratio are not significant most likely as most of the impact of the ratio on generation is already covered by allowing the coefficients to vary between the two price regimes. ${ }^{21}$ Coefficients on temperature are not significant.

TABLE 4. Detailed regression results for main specification.

\begin{tabular}{lcccc}
\hline \hline \multirow{2}{*}{ Regime } & \multicolumn{2}{c}{ Coal } & \multicolumn{2}{c}{ Gas } \\
& Cheap Coal & Fuel Switch & Cheap Coal & Fuel Switch \\
\hline \multirow{2}{*}{ Wind } & $-0.2409^{* * *}$ & $-0.2307^{* * *}$ & $-0.7591^{* * *}$ & $-0.7693^{* * *}$ \\
& $(0.0297)$ & $(0.0145)$ & $(0.0297)$ & $(0.0145)$ \\
Solar & $-0.2776^{* * *}$ & $-0.3468^{* * *}$ & $-0.7224^{* * *}$ & $-0.6532^{* * *}$ \\
& $(0.0208)$ & $(0.0170)$ & $(0.0208)$ & $(0.0170)$ \\
Demand & $0.2572^{* * *}$ & $-0.2400^{* * *}$ & $0.7428^{* * *}$ & $0.7600^{* * *}$ \\
& $(0.0067)$ & $(0.0044)$ & $(0.0067)$ & $(0.0044)$ \\
Capacity gas & $-0.0840^{* * *}$ & $-0.0614^{* * *}$ & $0.0840^{* * *}$ & $0.0614^{* * *}$ \\
& $(0.0286)$ & $(0.0089)$ & $(0.0286)$ & $(0.0089)$ \\
Capacity coal & $0.2185^{* * *}$ & $0.1952^{* * *}$ & $-0.2185^{* * *}$ & $-0.1952^{* * *}$ \\
Temperature & $(0.0249)$ & $(0.0177)$ & $(0.0249)$ & $(0.0177)$ \\
& -8.6380 & 6.0100 & 8.6380 & -6.0100 \\
Ratio & $(10.0917)$ & $(5.2625)$ & $(10.0917)$ & $(5.2625)$ \\
& -1170.7985 & -97.9131 & 1170.7958 & 97.9131 \\
& $(864.7601)$ & $(433.2517)$ & $(864.7601)$ & $(433.2517)$ \\
\hline Lagged variables & \multicolumn{2}{c}{ yes } & \multicolumn{2}{c}{0.997} \\
R-squared & \multicolumn{2}{c}{17495} \\
Observations & \multicolumn{2}{c}{17495} & \multicolumn{2}{c}{} \\
\hline \hline
\end{tabular}

Notes: Table shows the regression results of equation (9). The coefficients on RE denote the replacement of fossil generation in MWh induced by one MWh of wind and solar power, respectively. Cheap Coal refers to periods in which the coal-to-gas price ratio is below 0.74; Fuel Switch to the remaining periods. Heteroskedasticity robust standard errors are shown in parentheses. ${ }^{*},{ }^{* *},{ }^{* * *}$ : Significant at the $10 \%, 5 \%$ and $1 \%$ levels, respectively.

GENERATION IMPACT OF RE-The average marginal replacement of coal and gas generation by RE production for each fuel price regime is given by the

${ }^{21}$ Nevertheless the sign is as expected: An increase in the coal-to-gas price ratio, makes coal relatively more expensive. Therefore, the coefficient is positive for gas and negative for gas generation. Comparing these coefficients across the two fuel price regimes, we observe that the impact is higher for the cheap coal regime. This can be explained by the re-ordering of the merit-order curve in the fuel switch regime: As coal already moved to the right in the merit-order curve, an increase of the relative coal price does not induce a further change (see Figure 1). 
wind and solar coefficients:

$$
\delta_{i r \tilde{\phi}}^{Q}=\beta_{1 r i \tilde{\phi}} \quad \forall \tilde{\phi}, i, r,
$$

where $r$ denotes the renewable source, i. e., $r \in\{w, s\}$. I.e., the wind and solar coefficients in Table 4 show the change in coal and gas generation induced by an additional MWh of RE production.

Three major insights evolve. First, independent of the fuel price regime, one MWh RE production replaces in total one MWh of fossil generation, i.e., the impacts on coal and gas generation sum to one. This is expected as we assume demand to be inelastic in the short run. Thus, an increase of RE production leads to a decrease of fossil production of the same magnitude.

Second, gas shows a higher reaction to increasing RE generation than coal. This has most likely two reasons. On the one hand, the available capacity as well as observed generation is higher for gas-fired plants throughout our sample period (see Table 3). On the other hand, gas is expected to be the more flexible technology, and thus more likely to react to a change in residual demand due to lower dynamic cost components.

Third, moving from the cheap coal to the fuel switch regime, solar generation replaces more coal. For wind power we observe the opposite: a fuel switch leads to a higher displacement of gas but less coal generation. However, the effect is much less pronounced for wind than for solar. This highlights the profile effect induced through the change in the merit-order curve. Under fuel switch, coal generation becomes relatively more expensive, and thus moves to the right in the supply curve. In high demand hours, coal is therefore at the margin. As solar production coincides with high demand hours, solar becomes more effective in reducing coal generation (see Figure 2). The rather flat profile of wind generation explains the less pronounced reaction in the displacement of fossil generation. Wind is also available in night hours when under a fuel switch gas is likely to be at the margin. Thus, in the case of the UK a fuel switch leads to less coal but more gas replacement by wind power.

ROBUSTNESS CHECKS - As described in Section 3.3 and in greater detail in Appendix $\mathrm{C}$ we provide a set of sensitivity analyses to test the robustness of our results. Table C.2 shows the replacement effect of wind and solar power on coal and gas generation per regime $\left(\delta_{i r \tilde{\phi}}^{Q}\right)$. Overall, the replacement effects are stable across all specifications. A more detailed discussion including a comparison with the numerical results is provided in Appendix C.

\subsection{Emission Offset and Optimal Renewable Promotion}

IMPACT OF RE ON CARBON EMISSIONS - Using average emission coefficients, $e_{i}$ measured in $\mathrm{tCO}_{2} / \mathrm{MWh}_{e l}$, we obtain the marginal emission offset by renew- 
able resource $r:^{22}$

$$
\delta_{r \tilde{\phi}}^{E}=\sum_{i} e_{i} \delta_{i r \tilde{\phi}}^{Q}
$$

Table 5 shows that under cheap coal, solar power reduces emissions by $0.52 \mathrm{tCO}_{2} / \mathrm{MWh}$. Once a fuel switch is achieved, the marginal carbon offset by solar energy slightly increases by $8 \%$ to $0.56 \mathrm{tCO}_{2}$ per MWh. In contrast, the emissions impact of wind does (almost) not depend on the regime. On average it amounts to $0.50 \mathrm{tCO}_{2} / \mathrm{MWh}$ in both regimes.

The impact of the fuel switch on the marginal emission offset mimics the generation displacement effects. As the carbon price leads to a re-ordering of the supply curve with coal-fired plants moving to the right, solar power which is available in high demand hours becomes more effective. In contrast, wind shows almost no change in the replacement, and thus emissions impact.

TABLE 5. Emission and cost results per RE technology and regime

\begin{tabular}{|c|c|c|c|c|}
\hline & \multicolumn{2}{|c|}{ Solar } & \multicolumn{2}{|c|}{ Wind } \\
\hline & Cheap Coal & Fuel Switch & Cheap Coal & Fuel Switch \\
\hline $\begin{array}{l}\text { Marginal Emission Offset } \delta_{r}^{E} \\
{\left[\mathrm{tCO}_{2} / \mathrm{MWh}\right]}\end{array}$ & $\begin{array}{c}-0.52 \\
(0.02)\end{array}$ & $\begin{array}{l}-0.56 \\
(0.02)\end{array}$ & $\begin{array}{l}-0.50 \\
(0.03)\end{array}$ & $\begin{array}{l}-0.50 \\
(0.01)\end{array}$ \\
\hline \multicolumn{5}{|l|}{ Cost and Benefit $[€ / \mathrm{MWh}]$} \\
\hline Marginal Ext. Benefit & 26.08 & 27.84 & 25.14 & 24.88 \\
\hline Market Income & 43.29 & 38.35 & 40.47 & 38.81 \\
\hline Ext. Cost in Market Price & 14.98 & 15.89 & 14.44 & 14.20 \\
\hline Avoided Operating Cost & 28.31 & 22.46 & 26.03 & 24.61 \\
\hline \multicolumn{5}{|l|}{ Optimal Subsidy [€/MWh] } \\
\hline Optimal Feed-in & 54.39 & 50.30 & 51.17 & 49.49 \\
\hline Optimal RE premium & 11.10 & 11.95 & 10.70 & 10.68 \\
\hline
\end{tabular}

Notes: The marginal emssion offset is calculated according to equation (14). The marginal external benefit evaluates the marginal emission offset at a social cost of carbon of $50 € / \mathrm{tCO}$. The carbon value in the market price is derived as the average carbon price in the respective regime evaluated at the marginal emission offset. The optimal premium is the marginal external benefit net of the carbon value obtained through the market income (see equation 4). The optimal feed-in tariff is derived as the sum of operating cost avoided and the marginal external benefit (see equation 2). Cheap Coal refers to periods in which the coal-to-gas price ratio is below 0.74 ; Fuel Switch to the remaining periods.

\footnotetext{
${ }^{22}$ Average carbon coefficients $e_{i}$, are $0.38 \mathrm{t} \mathrm{CO}_{2} / \mathrm{MWh}$ for gas and $0.89 \mathrm{t} \mathrm{CO}_{2} / \mathrm{MWh}$ for coal, respectively. In reality, heat efficiencies, and therefore carbon emissions, depend on temperature, start-up and ramping of plants, i. e. they are not constant over time. As we do not observe hourly heat efficiencies or emissions, we use average emission coefficients for our analyses. This has the following implications: First, assuming that the infeed of RE leads to more fluctuations, and consequently ramping and start-ups, heat efficiencies are lower in times with high RE infeed. By using average heat efficiencies, we therefore tend to overestimate the impact on emissions. Second, solar energy is correlated with times of high temperatures during midday and summer when also heat efficiencies are low. Using average heat-efficiencies we, again, tend to overestimate the impact. Wind generation, on the other side, is higher in winter when heat efficiencies are high. Hence, in this case, we tend to underestimate the impact on emissions.
} 
CONSEQUENCES FOR OPTIMAL RENEWABLE PROMOTION_- The optimal feedin tariff is given as the sum of the marginal external benefit $(M E B)$ and the operating cost avoided (equation 2). In contrast, the optimal RE premium is equal to the $M E B$ net of the carbon value received through the market price (equation 4). Table 5 shows the optimal subsidies together with their different components which are presented in Figure 4 in a graphical way. Using a value of $50 € / \mathrm{tCO}_{2}$ for the social cost of carbon $(S C C)$ (Gillingham, 2019), we calculate the $M E B$ as the product of the RE specific emission offset and the social cost of carbon $\left(S C C \cdot \delta_{r}^{E}\right)$. We further calculate external cost reflected in the market prices as the product of the carbon price and the emission offset $\left(\tau \cdot \delta_{r}^{E}\right)$. Operating cost avoided are then calculated as the market income net of the external cost embedded in the price; where the market income given by the weighted average of the market prices using the $\mathrm{RE}$ profile as weight $\left(\sum_{t} \omega_{r t} \cdot P_{t}\right)$.

FIGURE 4. Optimal renewable production subsidies

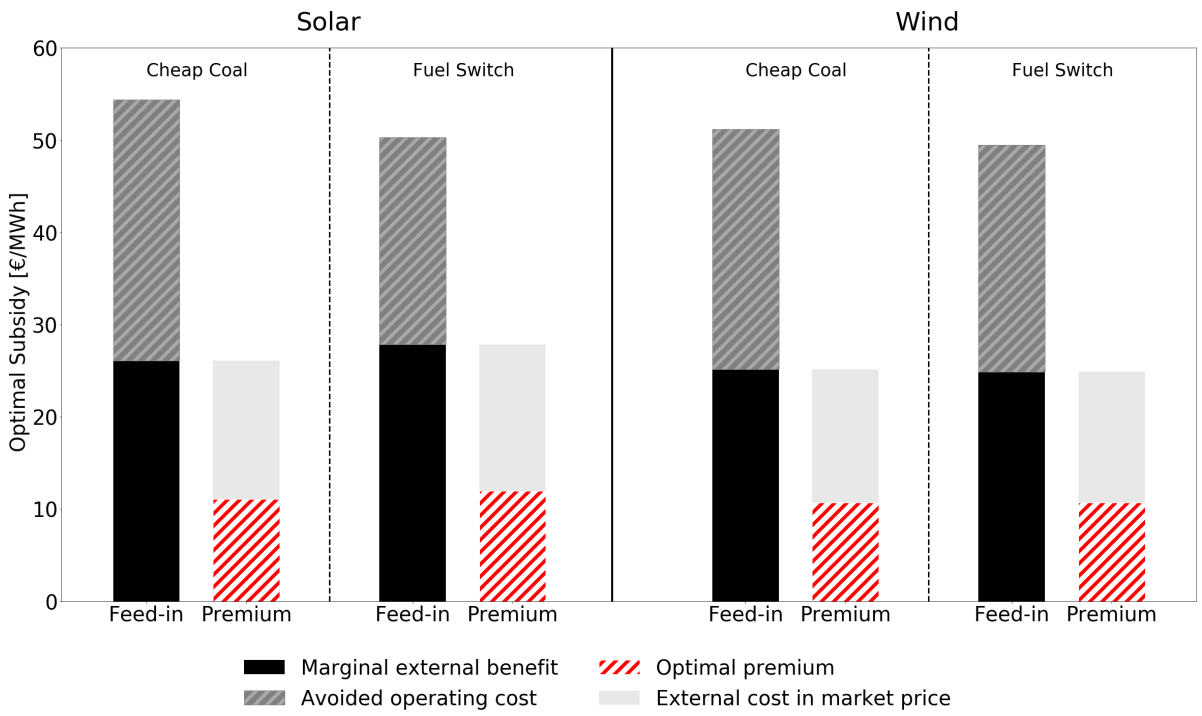

Notes: Shown are the optimal feed-in and premium values for solar and wind power depending on the fuel price regime. Single bars subdivide each subsidy into its components.

Considering the level of optimal subsidies, we make three major observations. First, the optimal premium and feed-in do not show a large variation across RE sources. Optimal feed-in tariffs lie between 49 and $54 € / \mathrm{MWh}$. Premiums are substantially lower in the order of 11 to $12 € /$ MWh. This confirms earlier results by Callaway et al. (2018) for the US and Abrell et al. (2019c) for Germany: Different production profiles of RE sources do not require a substantial differentiation of RE subsidies across RE sources.

Second, external cost reflected in the market price due to the carbon tax (grey boxes in Figure 4) substantially reduce RE premiums. Without a carbon price, the optimal premium would be equal to the $M E B$. In our sample period, the average carbon price was about $28.50 € / \mathrm{tCO}_{2}$ (see Table 3) leading to a substantial carbon value embedded in the market price. This reflection of 
external cost decreases the optimal premium to less than half of the $M E B$, i. e., from $25-28$ to $10-11 € / M W h$.

Third, feed-in tariffs do not show a large variation across fuel price regimes. A fuel switch requires adjusting the optimal feed-in by less than $8 \%$ downward. Also the adjustment of optimal premiums is relatively small. For solar, the optimal premium increases by about $8 \%$ as response to the re-ordering of the merit-order curve due to a fuel switch. In contrast, the optimal wind premium remains constant.

What drives the adjustments of the optimal subsidy rates? For the case of solar power, the fuel switch leads to an increase of the environmental effectiveness as more carbon-intense coal generation is substituted. Consequently, the $M E B$ increases, demanding an increase in the optimal premium. However, the re-ordering of the merit-order curve also implies that solar power receives an increased carbon value embedded in the market price. This dampens the effect of the increasing $M E B$ (see equation 5). As the environmental effectiveness of solar increases and as the carbon price is below the SCC, the overall effect is positive leading to an increase of the optimal premium by about $1 € / \mathrm{MWh}$ or $8 \%$. In contrast, the optimal solar feed-in decreases by $4 € / \mathrm{MWh}(8 \%)$. Under the fuel switch, coal plants move to the right in the merit-order which leads to a decrease in avoided operating cost. This decrease outweighs the effect of an increasing $M E B$.

For wind power, the fuel switch does not change the environmental effectiveness. Thus also the $M E B$, the carbon value received through the market income, and consequently the optimal premium remain almost constant. Avoided operating cost slightly decrease as gas prices are significantly lower in this regime. Consequently, as operating cost avoided slightly decrease while the $M E B$ remains (almost) constant, the optimal wind feed-in tariff slightly decreases by $1.70 € / \mathrm{MWh}(3 \%)$.

Comparing wind and solar subsidy rates, we observe that RE premiums naturally mimic the ranking imposed by environmental effectiveness. Under cheap coal, solar is less effective and, thus, receives a smaller premium. Once a fuel switch is achieved, the marginal emissions offset of solar power increases, leading to a higher optimal premium. These adjustments are driven by the environmental effectiveness, and the difference between carbon prices and the $S C C$. However, as carbon prices remain almost constant over the two periods, the impact of the latter is negligible. In contrast, feed-in tariffs are not directly affected by the carbon price, but only through its impact on the merit-order. However, under a feed-in system, adjustments are also driven by fuel prices as they impact operating cost avoided. Consequently, the ordering of technologies using environmental effectiveness does not necessarily reflect the ordering of feed-in tariffs.

Summarizing, our empirical analysis provides three main findings. First, the carbon value received through the market price substantially reduces the optimal RE premium. Second, optimal feed-in tariffs and premiums need to be adjusted to account for a fuel-switch. This adjustment is rather small in absolute terms. In relative terms, it is larger for RE premiums than for feedin tariffs. Third, we find some variation of environmental effectiveness across RE sources. The differentiation of optimal subsidy rates across RE sources is, however, rather modest.

ROBUSTNESS CHECKS - Table 6 shows the optimal feed-in tariffs and opti- 
mal premiums for the different specifications. Given that the replacement effects of wind and solar are stable across specifications (see Appendix C), also the optimal subsidies are very robust to varying econometric specifications. Moreover, the results from the numerical model are also similar but slightly differ in size. Relative subsidy adjustments triggered by a fuel switch are the same in the numerical and the econometric approach but adjustments in the numerical approach are slightly more pronounced. ${ }^{23}$

TABLE 6. Optimal subsidy per RE technology and regime [€/MWh] for different specifications and numerical model results

\begin{tabular}{|c|c|c|c|c|}
\hline & \multicolumn{2}{|c|}{ Solar } & \multicolumn{2}{|c|}{ Wind } \\
\hline & Cheap Coal & Fuel Switch & Cheap Coal & Fuel Switch \\
\hline $\begin{array}{l}\text { Optimal feed-in } \\
\text { Main Specification }\end{array}$ & 54.39 & 50.30 & 51.17 & 49.49 \\
\hline $\begin{array}{l}\text { Specifications with tir } \\
\text { Hour FE } \\
\text { Month FE } \\
\text { MonthxYear FE }\end{array}$ & $\begin{array}{r}\text { effects } \\
54.21 \\
54.30 \\
54.29\end{array}$ & $\begin{array}{l}50.08 \\
50.19 \\
50.14\end{array}$ & $\begin{array}{l}51.10 \\
51.18 \\
51.18\end{array}$ & $\begin{array}{l}49.49 \\
49.51 \\
49.49\end{array}$ \\
\hline $\begin{array}{l}\text { Specifications with di } \\
\begin{array}{l}\hat{\phi}=0.7 \\
\hat{\phi}=0.8\end{array}\end{array}$ & $\begin{array}{c}\text { threshold levels } \\
53.80 \\
54.80\end{array}$ & $\begin{array}{l}50.21 \\
50.03\end{array}$ & $\begin{array}{l}51.16 \\
51.24\end{array}$ & $\begin{array}{l}49.58 \\
49.33\end{array}$ \\
\hline $\begin{array}{l}\text { Flexible and semi-par } \\
\text { Polynomials } \\
\text { RE Quintiles } \\
\text { Demand Quintiles }\end{array}$ & $\begin{array}{c}\text { specifications } \\
55.08 \\
54.40 \\
54.49\end{array}$ & $\begin{array}{l}50.77 \\
50.30 \\
50.02\end{array}$ & $\begin{array}{l}51.27 \\
51.31 \\
51.15\end{array}$ & $\begin{array}{l}49.74 \\
49.51 \\
49.51\end{array}$ \\
\hline Simulation Model & 59.97 & 54.67 & 61.26 & 55.81 \\
\hline $\begin{array}{l}\text { Optimal RE premi } \\
\text { Main Specification }\end{array}$ & 11.10 & 11.95 & 10.70 & 10.68 \\
\hline $\begin{array}{l}\text { Specifications with tir } \\
\text { Hour FE } \\
\text { Month FE } \\
\text { MonthxYear FE }\end{array}$ & $\begin{array}{r}\text { effects } \\
10.93 \\
11.01 \\
11.00\end{array}$ & $\begin{array}{l}11.73 \\
11.84 \\
11.79\end{array}$ & $\begin{array}{l}10.63 \\
10.71 \\
10.71\end{array}$ & $\begin{array}{l}10.68 \\
10.70 \\
10.69\end{array}$ \\
\hline $\begin{array}{l}\text { Specifications with di } \\
\qquad \begin{array}{l}\hat{\phi}=0.7 \\
\hat{\phi}=0.8\end{array}\end{array}$ & $\begin{array}{c}\text { threshold levels } \\
10.52 \\
11.51\end{array}$ & $\begin{array}{l}11.86 \\
11.68\end{array}$ & $\begin{array}{l}10.69 \\
10.77\end{array}$ & $\begin{array}{l}10.77 \\
10.52\end{array}$ \\
\hline $\begin{array}{l}\text { Flexible and semi-par } \\
\text { Polynomials } \\
\text { RE Quintiles } \\
\text { Demand Quintiles }\end{array}$ & $\begin{array}{c}\text { specifications } \\
11.79 \\
11.11 \\
11.21\end{array}$ & $\begin{array}{l}12.42 \\
11.95 \\
11.67\end{array}$ & $\begin{array}{l}10.80 \\
10.84 \\
10.68\end{array}$ & $\begin{array}{l}10.93 \\
10.70 \\
10.70\end{array}$ \\
\hline Simulation Model & 8.26 & 11.83 & 12.34 & 12.07 \\
\hline
\end{tabular}

Notes: The optimal premium is the marginal external benefit net of the carbon value obtained through the market income (see equation 4). The optimal feed-in tariff is derived as the sum of avoided operating cost and the marginal external benefit (see equation 2). Cheap Coal refers to periods in which the coal-to-gas price ratio is below the defined threshold; Fuel Switch to the remaining periods.

\footnotetext{
${ }^{23}$ For a more detailed discussion see Appendix C
} 


\section{The Impact of Carbon Prices on Renewable Energy Support}

Our estimation allows quantifying the impact of a fuel switch on the optimal premium and feed-in tariff. However, as the carbon price is on average almost equal across the two regimes (see Table 3), we are not able to show the impact of a change of the carbon price itself. We therefore use a simulation model (see Section 3.4) to illustrate the impact of increasing carbon prices on optimal RE subsidies. In the following, we first describe the simulation setup and then present the respective results.

\subsection{Simulation Setup and Calculation of Optimal Subsidies}

We simulate the impact of increasing carbon prices under constant fuel prices. We keep fuel prices constant at the level observed at the beginning of our sample. On 1 January 2015 the coal (gas) price was $8.3(21.3) € / \mathrm{MWh}_{t h}$. Given these prices, the merit-order curve is completely separated in the sense that all coal-fired plants are dispatched before gas-fired ones. We then increase the carbon price from 0 to $50 € / \mathrm{tCO}_{2}$ in steps of $1 €$. All other parameters, in particular hourly available capacities and heat efficiencies, are kept at their observed values. Thus, these simulations enable us to explore the impact of carbon prices under the given set of fuel prices.

Using the simulated hourly dispatch, we calculate the marginal generator for each hour (see Section 3.4) The individual plan characteristics of the marginal generator then allow us to compute the marginal emissions rate (MER) as well as operating cost avoided for each hour. Finally, we use the production profile of RE sources $\left(\omega_{r t}\right)$, the social cost of carbon (SCC), and hourly electricity prices simulated by the model, to calculate the optimal feed-in and premium by RE source according to equations (2) and (4).

\subsection{Results}

Figure 5 presents the marginal external benefit (MEB, black solid line) as well as the optimal feed-in tariff (upper red line) and premium (lower red line) derived from our simulations. Again, we distinguish between wind and solar power. As the optimal feed-in grants a subsidy equal to the sum of the marginal external benefit and the avoided operating cost (see equation 2), the distance between the optimal feed-in and the MEB shows the operating cost avoided. The distance between the MEB and the optimal premium represents the carbon rent transferred through the market price.

MARGINAL EXTERNAL BENEFIT_- The MEB stays constant until a carbon price of $15 € / \mathrm{tCO}_{2}$. At this point, the most efficient gas plant (Pembroke) becomes cheaper than the most inefficient coal plant (Uskmouth), i.e., fuel switching begins. By further increasing the carbon price, coal-fired plants move to the right in the merit-order curve, and we observe that the MEB of both — wind and solar power — increases.

OPTIMAL PREMIUM - The optimal premium is equal to the MEB net of the carbon value embedded in the market price. As no fuel switching occurs before a carbon price of $15 € / \mathrm{tCO}_{2}$, the MEB is constant. Thus the optimal premium linearly decreases, reflecting the increased carbon price component embedded in the electricity price. Later - although the MEB slightly increases - the premium is further decreasing in the carbon price. This implies that the dampening effect of the carbon price signal in the market price clearly 
Figure 5. Optimal RE subsidies by carbon price

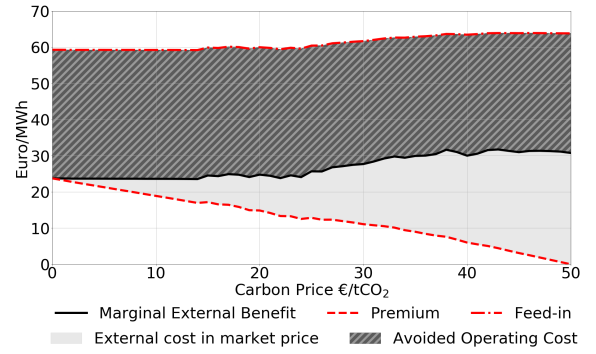

(a) Wind

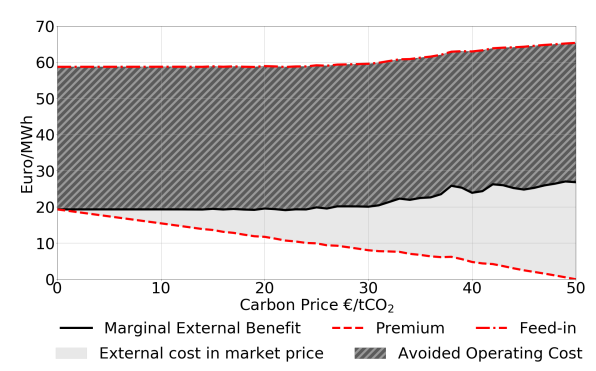

(b) Solar

Notes: The graph shows the marginal external benefit (solid), optimal feed-in (dashed), and optimal premium (dotted) by carbon price resulting from the simulations for wind (left panel) and solar (right panel) power. For each carbon price, the distance between MEB and the feed-in indicates operating cost avoided. The distance between MEB and the premium has the interpretation of the carbon rent transferred through the market price. The distance between the optimal feed-in and premium, i.e., the sum of the external cost in market price and avoided operating cost, is equal to the average market income.

outweighs the increasing effect induced by a higher environmental effectiveness. Once carbon emissions are priced at the social cost of carbon, external costs are fully reflected in the market price and, thus, the optimal premium is zero.

OPTIMAL FEED-IN TARIFF-The optimal feed-in is the sum of the MEB and the avoided operating cost. Low values of the carbon price do not alter the merit-order curve. Thus the MEB, the operating cost avoided, and consequently also the optimal feed-in tariff remain constant. At higher values of the carbon price, a further increase leads to a higher optimal feed-in tariff. When coal plants move to the right in the merit-order curve, this has two effects on the optimal feed-in tariff: On the one hand, the marginal emission rate, and thus the MEB, increases. On the other hand, given constant fuel prices, the avoided operating cost (net-of-carbon) are cheaper for coal than for gas plants. Thus, operating cost avoided decrease. Overall the increase in the MEB exceeds the dampening effect of lower operating cost leading to a slight increase of the feed-in tariff.

The difference between the optimal premium and feed-in depicts the part of the marginal economic benefit that $\mathrm{RE}$ generators are able to gain at the market and is equal to the average market income. Due to the increasing reflection of carbon cost, this income is increase which phases out premiums. Once carbon is optimally priced, the average market income is equal to the optimal feed-in. Therefore, under an optimal carbon price, there is also no need to implement feed-in tariffs.

Summarizing, RE premiums clearly decrease in carbon prices as the reflection of external costs in the market price increases. Consequently, at high carbon prices, RE premiums are no longer needed to foster investment into RE. Optimal feed-in tariffs need only small adjustments to account for increasing carbon prices. However, that does not necessarily imply that feed-ins do not become redundant. Once carbon is optimally priced, optimal feed-ins are equal to the average market income. 


\section{Conclusions}

For many years, renewable promotion schemes have been the predominant policy to decarbonize the electricity sector. However, in recent years, carbon pricing is becoming more and more popular, leading to an increase in carbon prices. This paper addresses the question how renewable energy support (RES) needs to be adjusted once external cost of carbon emissions are increasingly priced. More specifically we ask: How does a carbon price change the emissions impact of wind and solar generation? What are the implications of carbon prices for the optimal support of RE generation?

To address these questions, we first analytically derive the optimal feed-in tariff and RE premium under carbon pricing. We then empirically estimate the impact of a fuel switch on RE-induced abatement using hourly data of the UK power market for the years 2015/16. We choose the UK as it was subject to extensive RES schemes and a high carbon tax due to the Carbon Price Support. We calculate the optimal feed-in tariff and premium for wind and solar for a situation with and without fuel switch. Finally, we use a numerical model of the UK power market to derive the impact of increasing carbon prices on the optimal RE subsidy.

The optimal feed-in reflects the emissions avoided evaluated at the social cost of carbon as well as avoided cost of conventional generation. In contrast, the optimal RE premium reflects only the value of avoided emissions that is not addressed by the carbon price. Increasing carbon prices therefore require adjusting RE subsidies due to two motives: The change in the marginal external benefit of RE production and the increasing reflection of the external cost of carbon in the market price.

The first motive only applies if the carbon price leads to a fuel switch. In this case, the ordering in the market supply curve changes, leading to a change in the marginal generator. This affects the impact of $\mathrm{RE}$ on emissions, i.e., their marginal external benefit, as well as the costs of fossil generation. Our empirical analysis shows, that a fuel switch induces a rather modest adjustment of optimal RE subsidies. For the UK, we estimate a maximum adjustment of optimal premiums and feed-in tariffs of around 8\%. Adjustments differ across $\mathrm{RE}$ sources due to their distinct production profiles. As solar generation is highly correlated with demand, the marginal coal offset, and thus the marginal external benefit of solar, increases with a fuel switch. In contrast, for wind with its profile being rather flat over the day, the estimated adjustment is negligible.

The second motive only applies to optimal premiums which decrease with the carbon tax as the higher carbon value is reflected in the market price. Our numerical results show that the necessary adjustment is substantial. We also find that the decrease in the premium due to an increasing reflection of the cost of carbon in the market price always dominate the potential increase of the marginal external benefit induced by a fuel switch. Once carbon is optimally priced, there is no further room for RE premiums, i.e., premiums decrease to zero.

At the time of our analysis, the UK electricity market was characterized by a diverse capacity mix including coal and gas-fired plants. However, many countries do not have coal capacities installed or are about to phase-out coalfired plants through additional policies. What do our results imply for these countries? As long as gas capacities exist and are at the margin, carbon pricing 
cannot induce a fuel switch. Consequently, the adjustment of RE subsidies for a change in marginal emissions avoided is no longer required. In contrast, adjusting RE premiums to account for increasing carbon prices is still necessary.

As feed-in tariffs do not need to be adjusted to account for external cost in the market price, they seem to be less susceptible to the overlap of policies. However, this stability comes at a cost: Feed-in tariffs decouple RE generation from the wholesale electricity market. They thus need to be adjusted to reflect avoided cost of fossil producers. In contrast, RE premiums do not need to be adjusted for these changes as they receive the market price.

Summarizing, if policy makers increasingly rely on carbon pricing, the role of $\mathrm{RE}$ support decreases. Once carbon is priced optimally, there is no more room for RE premiums. If RE premiums are not adjusted accordingly, there is the danger of over-investment into RE sources. Feed-in tariffs, in contrast, decouple RE generation from the market. Thus, they do not need to be adjusted for the carbon values embedded in the market price. However, once carbon is optimally priced, the optimal feed-in tariff equals the average market income, also making the subsidy redundant. 


\section{References}

Abrell, J., Kosch, M., \& Rausch, S. (2019a). The Economic Cost of Carbon Abatement with Renewable Energy Policies. Journal of Public Economics, $196,172-202$.

Abrell, J., Kosch, M., \& Rausch, S. (2020). How Effective Was the UK Carbon Tax? A Machine Learning Approach to Policy Evaluation. Working Paper.

Abrell, J., Rausch, S., \& Streitberger, C. (2019b). Buffering volatility: Storage investments and technology-specific renewable energy support. Energy Economics, 84, 1-15.

Abrell, J., Rausch, S., \& Streitberger, C. (2019c). The Economics of Renewable Energy Support. Journal of Public Economics, 176, 94-117.

Abrell, J., \& Weigt, H. (2008). The interaction of emissions trading and renewable energy promotion. Dresden University of Technology Working Paper no. WP-EGW-05.

Böhringer, C., \& Behrens, M. (2015). Interactions of emission caps and renewable electricity support schemes. Journal of Regulatory Economics, 48 , 78-98.

Böhringer, C., \& Rosendahl, K. E. (2010). Green promotes the dirtiest: on the interaction between black and green quotas in energy markets. Journal of Regulatory Economics, 37, 316-325.

Callaway, D. S., Fowlie, M., \& McCormick, G. (2018). Location, location, location: The variable value of renewable energy and demand-side efficiency resources. Journal of the Association of Environmental and Resource Economists, 5, 39-75.

CMA (2016). Competition and markets autority: Energy market investigation,

Cullen, J. (2013). Measuring the environmental benefit of wind-generated electricity. American Economic Journal: Economic Policy, 5(4), 107-133.

Cullen, J. A., \& Mansur, E. T. (2017). Inferring carbon abatement costs in electricity markets: A revealed preference approach using the shale revolution. American Economic Journal: Economic Policy, 9, 106-33.

Departement for Business, Energy \& Industrial Strategy (2017). Policy paper - Contracts for Differences www.gov.uk/government/publications/contracts-for-difference/contract-fordifference.

DTI (2017). Reform of the Renewables Obligation.

DUKES (2017). Digest of UK Energy Statistics: Chapter 6 - Renewable Sources of Energy.

ECA\&D (2016). European Climate Assessment \& Data. 
ECB (2017). European central bank: Daily exchange rates. www.ecb.europa.eu.

EEX (2018). European energy exchange: Daily spot prices eu emission allowances. www.eex.com/en/market-data/environmental-markets/spotmarket/european-emission-allowances.

EIKON (2007). Thomson reuters EIKON database.

ELEXON (2016). ELEXON. www.elexon.co.uk.

European Commission (2016). DG Climate Action: Euroepan Union Transaction Log; http://ec.europa.eu/environment/ets.

Fell, H., \& Kaffine, D. T. (2018). The fall of coal: Joint impacts of fuel prices and renewables on generation and emissions. American Economic Journal: Economic Policy, 10, 90-116.

Gillingham, K. (2019). Carbon calculus. Finance $\&$ Development, .

Gonzalez, P. d. R. (2007). The interaction between emissions trading and renewable electricity support schemes. an overview of the literature. Mitigation and Adaptation Strategies for Global Change, 12, 1363-1390.

Hirst, D. (2017). Carbon Price Floor (CPF) and the price support mechanism. House of Commons - Briefing paper.

HM Revenue \& Customs (2014). Carbon Price Floor: Reform. www.gov.uk/government/publications/carbon-price-floor-reform.

Holladay, J. S., \& LaRiviere, J. (2017). The impact of cheap natural gas on marginal emissions from electricity generation and implications for energy policy. Journal of Environmental Economics and Management, 85, 205227 .

Holladay, J. S., \& Soloway, S. (2016). The environmental impacts of fuel switching electricity generators. The Energy Journal, Volume 37.

IPCC (2006). Revised 1996 IPCC Guidelines for National Greenhouse Gas Inventories. IPCC.

Kaffine, D. T., McBee, B. J., \& Lieskovsky, J. (2013). Emissions savings from wind power generation in texas. The Energy Journal, 34, 155-175.

Lamp, S., \& Samano, M. (2020). (Mis)allocation of renewable energy sources. TSE Working Paper, .

Mansur, E. T. (2008). Measuring welfare in restructured electricity markets. The Review of Economics and Statistics, 90(2), 369-386.

Nationalgrid (2011). Electricity Ten Year Statement 2011 - Appendix F. www.nationalgrid.com/uk/publications/electricity-ten-year-statement-etys.

Nationalgrid (2016). Final electricity demand. www2.nationalgrid.com/UK/Industry-information/Electricity-transmissionoperational-data/Data-Explorer. 
Novan, K. (2015). Valuing the wind: Renewable energy policies and air pollution avoided. American Economic Journal: Economic Policy, 7, 291-326.

Reguant, M. (2014). Complementary bidding mechanisms and startup costs in electricity markets. Review of Economic Studies, 81(4), 708-1742.

Schröder, A., Kunz, F., Meiss, J., Mendelevitch, R., \& Hirschhausen, C. (2013). Current and prospective costs of electricity generation until 2050. German Institute for Economic Research (DIW) Berlin Discussion Paper, 2013-68, $1-94$.

Variable Pitch (2016). Variable Pitch. www.variablepitch.co.uk.

Weigt, H., Ellerman, D., \& Delarue, E. (2012). $\mathrm{CO}_{2}$ abatement from renewables in the German electricity sector: Does a $\mathrm{CO}_{2}$ price help? Energy Economics, 40, Supplement 1, S149-S158.

Worldbank (2020). State and Trends of Carbon Pricing 2020. Technical Report The Wordbank Group. 


\section{Appendix A. Detailed Information on RES schemes in the UK}

Small-scale generation, mostly solar photovoltaics, is mainly promoted by feed-in tariffs (FITs) which pay a fixed price per unit of generation. The level of contribution depends on the technology, installed capacity and the installation date (DUKES, 2017). For large-scale generation, the most important support mechanism until 2015 was the Renewable Obligations (RO) scheme. This obliged electricity firms to sell a minimum share of RE generation-measured against their total electricity sales. For each unit of RE generation they received a tradable certificate. At first, each MWh of RE generation received one certificate. Starting from 2009, the scheme was adapted and the sources received different amounts of certificates per unit of generation - depending on their relative maturity, development cost and associated risk (DTI, 2017). For example, on-shore wind received less then one certificate per MWh while offshore wind received almost two certificates per MWh. From 2015 until 2017, the RO scheme closed bit by bit for all RE sources and was replaced by the Contract for Differences (CfD), which ensure a fixed price for renewable electricity generation. When the wholesale market price lies below this strike price, the generators receive the difference, when it lies above the strike price, they have to pay the difference (Departement for Business, Energy \& Industrial Strategy, 2017).

\section{Appendix B. Data Sources and Construction}

In the following, we present data sources and construction of all variables that we either use in our models or for ex-post calculations.

For coal and gas generation we use "final physical notification" (FPN) data provided by the operator of the UK electricity balancing system ELEXON (2016). These data represent hourly generation of each fossil power plant unit. FPN reports the final, 5 minutes before delivery time generation announcement of power plant owners to the grid operator. Although the grid operator might adjust this announcement due to the need for balancing power or re-dispatching measures, they are a reasonable measure for generation, which is not directly observable for UK power plants. For our analysis, we aggregate power plant units to the technologies coal and gas.

ELEXON (2016) provides hourly RE generation. These data, however, only report solar and wind in-feeds into to the high voltage grid. Nationalgrid (2016) reports final demand together with an estimate of wind and solar generation embedded in demand. Adding embedded RE generation to wind and solar generation provided by ELEXON (2016), we construct a measure of RE production.

CPS rates are reported by Hirst (2017) and HM Revenue \& Customs (2014), and the EUA price by EEX (2018). Fuel prices come from EIKON (2007). For coal, we use the ICE CIF ARA Near Month future. Natural gas prices are NBP Hub 1st day futures. All prices are converted to Euro using daily exchange rates provided by ECB (2017). Note that the CPS rate is an annually constant tax in British Pound but reflects exchange rate variations due to the Euro conversion.

Annual carbon emissions for each plant are taken from the official registry of the EUTL (European Commission, 2016). Dividing total emissions by total generation per technology, we obtain technology-specific average emission rates, 
Figure B.1. Carbon prices necessary to induce a fuel switch.

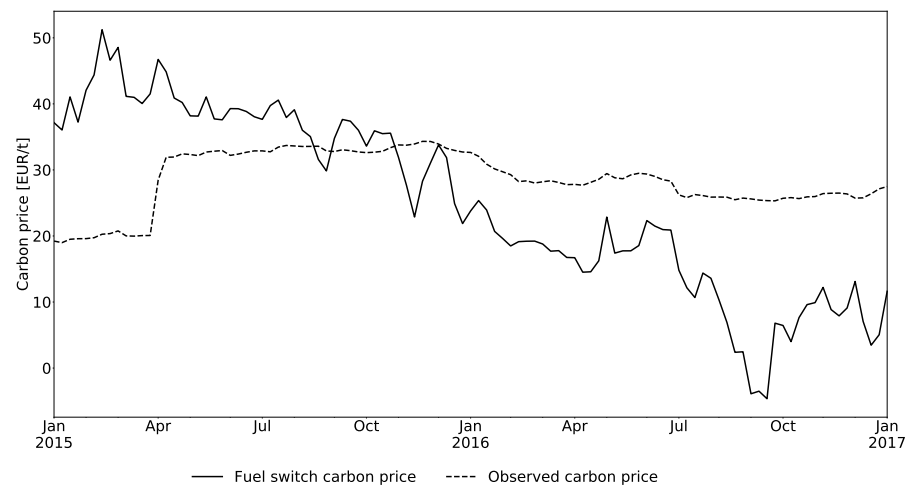

Notes: The average weekly carbon price to induce a fuel switch is derived from a fuel switch ratio of 0.74 and equation (10).

$e_{i}$, which are significantly higher for coal $\left(0.89 \mathrm{t} \mathrm{CO}_{2} / \mathrm{MWh}\right)$ than for gas $(0.38 \mathrm{t}$ $\mathrm{CO}_{2} / \mathrm{MWh}$ ).

Using fuel-specific emission factors $\theta_{i}^{\text {fuel }}$ per MWh of thermal energy, ${ }^{24}$ we calculate average heat efficiencies per technology, $\eta_{i}=\theta_{i} / e_{i}$. It is $51 \%$ for natural gas and $38 \%$ for coal plants.

Average heat efficiencies are used to derive the fuel price ratio that induces a fuel switch (see Section 3.3). Figure B.1 shows the carbon prices that are necessary to induce a fuel switch (i. e., coal-to-gas price ratio above 0.74 ), and compares it to the observed carbon prices.

Installed capacities, fuel type, and plant closure dates are provided by Variable Pitch (2016) and Nationalgrid (2011). In case the 95\% quantile of observed generation exceeds provided installed capacity, we adjust capacity to the $95 \%$ quantile of generation. Available hourly capacity is given by the Maximum Export Limits (MEL) provided by ELEXON (2016), which we aggregate to the technology level. Daily mean temperatures are provided by ECA\&D (2016).

Table B.1 shows average heat efficiencies of power plants used in the numerical model. Schröder et al. (2013) provide a survey on power plant cost data including ramping cost. We use a value of $10(1.5) € / \mathrm{MW}_{\text {started }}$ for coal (gas) plants. Additional fuel use $\left(c_{i}^{f+}\right)$ is given as 6.2 (3.5) $\mathrm{MWh}_{\text {therm }} / \mathrm{MWh}_{e l}$.

\section{Appendix C. Robustness Checks}

To examine the sensitivity of our results with regard to several assumptions we perform different robustness checks. First, we introduce different fixed effects to our main specification examining the robustness with regard to unobserved factors. Second, we examine more flexible estimations using higher order polynomials and semi-parametric approaches. Third, we examine the robustness of our results with regard to the threshold price ratio dividing the sample into the two price regimes. Finally, we also compare the regression results against

${ }^{24} 0.34 \mathrm{tCO}_{2} / \mathrm{MWh}_{\text {therm }}$ for coal and $0.20 \mathrm{tCO}_{2} / \mathrm{MWh}_{\text {therm }}$ for gas (IPCC, 2006). 
TABle B.1. Power Plants and Heat Efficiencies

\begin{tabular}{|c|c|c|c|c|c|}
\hline Gas Plant & $\begin{array}{c}\text { Capacity } \\
{[\mathrm{MW}]}\end{array}$ & Efficiency & Coal Plant & $\begin{array}{c}\text { Capacity } \\
{[\mathrm{MW}]}\end{array}$ & Efficiency \\
\hline Pembroke & 2269 & 0.60 & Longannet & 2304 & 0.42 \\
\hline Staythorpe & 1792 & 0.58 & Didcot Coal & 2108 & 0.39 \\
\hline Didcot CCGT & 1404 & 0.55 & Ratcliffe & 2000 & 0.38 \\
\hline Connahs Quay & 1380 & 0.48 & West Burton Coal & 1972 & 0.38 \\
\hline West Burton CCGT & 1332 & 0.51 & Fiddlers Ferry & 1961 & 0.37 \\
\hline Grain CHP & 1305 & 0.56 & Ferrybridge & 1960 & 0.38 \\
\hline South Humber & 1239 & 0.50 & Drax Coal & 1947 & 0.38 \\
\hline Seabank & 1169 & 0.55 & Eggborough & 1932 & 0.37 \\
\hline Saltend South & 1164 & 0.52 & Aberthaw & 1641 & 0.41 \\
\hline Immingham CHP & 1123 & 0.44 & Rugeley & 996 & 0.39 \\
\hline Langage & 905 & 0.55 & Uskmouth & 363 & 0.33 \\
\hline Marchwood & 898 & 0.58 & Average & coal plant & 0.38 \\
\hline Killingholme & 854 & 0.48 & Average coal plant & (weighted) & 0.39 \\
\hline Severn & 850 & 0.54 & & & \\
\hline Spalding & 830 & 0.54 & & & \\
\hline Rocksavage & 800 & 0.53 & & & \\
\hline Sutton Bridge & 796 & 0.52 & & & \\
\hline Damhead Creek & 783 & 0.53 & & & \\
\hline Coryton & 770 & 0.52 & & & \\
\hline Little Barford & 740 & 0.54 & & & \\
\hline Rye House & 715 & 0.43 & & & \\
\hline Medway & 680 & 0.53 & & & \\
\hline Baglan Bay & 520 & 0.57 & & & \\
\hline Deeside & 498 & 0.47 & & & \\
\hline Great Yarmouth & 420 & 0.56 & & & \\
\hline Shoreham & 420 & 0.54 & & & \\
\hline Enfield Energy & 408 & 0.53 & & & \\
\hline Corby & 401 & 0.39 & & & \\
\hline Cottam CCGT & 395 & 0.55 & & & \\
\hline Brigg & 240 & 0.38 & & & \\
\hline Barry & 235 & 0.42 & & & \\
\hline Roosecote & 221 & 0.45 & & & \\
\hline Shotton CHP & 210 & 0.46 & & & \\
\hline Derwent & 198 & 0.51 & & & \\
\hline Fellside & 180 & 0.51 & & & \\
\hline Fawley Cogen & 150 & 0.51 & & & \\
\hline Grangemouth & 144 & 0.51 & & & \\
\hline Fife & 123 & 0.51 & & & \\
\hline \multicolumn{2}{|c|}{ Average gas plant } & 0.51 & & & \\
\hline \multicolumn{2}{|c|}{ Average gas plant (weighted) } & 0.53 & & & \\
\hline
\end{tabular}

Notes: Adapted from Abrell et al. (2020) dropping plants closing before 2015. We show installed capacities as indicator whereas we use available capacity in each hour in the estimation and numerical approach. 
a counterfactual approach using our simulation model. Table C.2 provides an overview of the robustness results showing the RE-induced fossil replacement for the different specifications. Overall, we conclude that our results are robust to varying specifications. In the subsequent sections, we explain and analyze the results of each specification in detail.

\section{Appendix C.1. Specifications with Time Fixed Effects}

To examine the impact of unobserved variables varying at the hourly or monthly level, we include a set of time fixed effects, $\boldsymbol{D}_{\boldsymbol{t}}$, to our main specification given by equation (9). We include three different time dummies: hour of the day (Hour FE), month in the year (Month FE), and month of the sample (MonthxYear FE), respectively.

Table C.2 shows that our results are mostly robust to the inclusion of fixed effects. The impact of wind on coal and gas generation is (almost) not affected by the inclusion of time fixed effects. In the case of solar, the impact of solar on coal (gas) slightly decreases (increases) when including time fixed effects. Given that solar has a very pronounced daily and seasonal profile, it is likely that time fixed effects absorb some variation of solar generation.

\section{Appendix C.2. Specifications with Alternative Threshold Levels for $\phi$}

In our main specification, the threshold level that divides the two fuel price regimes is given by a coal-to-gas price ratio of 0.74 at which marginal cost for coal and gas generation are on average equal. To address the sensitivity of our results with respect to this parameter choice, we add two more specifications: One, where we define the threshold ratio to be at 0.7 ; and one where it is 0.8 . Using these alternative parameters, we re-estimate equation (9).

Table C.2 shows that the impacts of wind on fossil generation are almost not affected by a change in the threshold ratio. Only in the case of solar replacement in the cheap coal regime, there is a slightly higher difference between the specifications: A lower threshold level leads to a lower reaction of coal. This result would be expected as a lower threshold level indicates a clearer separation between coal and gas generation in the merit-order during the cheap coal regime. Thus, coal is only marginal in low demand hours when solar is less active. In case of a higher threshold level, the opposite is the case, i. e., a more mixed merit-order curve indicates that coal can also be marginal in higher demand hours, increasing the impact of solar on coal. Due to its flat profile, wind replacement is (almost) not affected by a change in the threshold ratio.

\section{Appendix C.3. Flexible and semi-parametric specifications}

To allow for non-linear effects we estimate one specification where we include higher-order polynomials of wind and solar power as well as demand, and two semi-parametric specifications where we allow coefficients to vary for different $\mathrm{RE}$ generation and demand levels.

\section{Appendix C.3.1. Higher order polynomials}

In this specification we include second and third order polynomials of wind and solar power as well as demand: 
TABLE C.2. Marginal fossil generation displacement of renewable energies

\begin{tabular}{|c|c|c|c|c|}
\hline & \multicolumn{2}{|c|}{ Solar } & \multicolumn{2}{|c|}{ Wind } \\
\hline & Cheap Coal & Fuel Switch & Cheap Coal & Fuel Switch \\
\hline \multicolumn{5}{|l|}{ Coal } \\
\hline Main Specification & $\begin{array}{l}-0.28 \\
(0.02)\end{array}$ & $\begin{array}{l}-0.35 \\
(0.02)\end{array}$ & $\begin{array}{l}-0.24 \\
(0.03)\end{array}$ & $\begin{array}{l}-0.23 \\
(0.01)\end{array}$ \\
\hline \multicolumn{5}{|c|}{ Specifications with time fixed effects } \\
\hline $\begin{array}{l}\text { Hour FE } \\
\text { Month FE } \\
\text { MonthxYear FE }\end{array}$ & $\begin{array}{c}-0.26 \\
(0.02) \\
-0.27 \\
(0.02) \\
-0.27 \\
(0.02)\end{array}$ & $\begin{array}{l}-0.33 \\
(0.02) \\
-0.34 \\
(0.02) \\
-0.33 \\
(0.02)\end{array}$ & $\begin{array}{l}-0.23 \\
(0.03) \\
-0.24 \\
(0.03) \\
-0.24 \\
(0.03)\end{array}$ & $\begin{array}{c}-0.23 \\
(0.01) \\
-0.23 \\
(0.01) \\
-0.23 \\
(0.01)\end{array}$ \\
\hline \multicolumn{5}{|c|}{ Specifications with different threshold levels $\hat{\phi}$} \\
\hline$\hat{\phi}=0.7$ & $\begin{array}{l}-0.22 \\
(0.03)\end{array}$ & $\begin{array}{l}-0.34 \\
(0.01)\end{array}$ & $\begin{array}{l}-0.24 \\
(0.04)\end{array}$ & $\begin{array}{l}-0.24 \\
(0.01)\end{array}$ \\
\hline$\hat{\phi}=0.8$ & $\begin{array}{l}-0.32 \\
(0.02)\end{array}$ & $\begin{array}{l}-0.32 \\
(0.02)\end{array}$ & $\begin{array}{l}-0.25 \\
(0.02)\end{array}$ & $\begin{array}{l}-0.22 \\
(0.02)\end{array}$ \\
\hline \multicolumn{5}{|c|}{ Flexible and semi-parametric specifications } \\
\hline Polynomials & $\begin{array}{l}-0.31 \\
(0.03)\end{array}$ & $\begin{array}{l}-0.39 \\
(0.03)\end{array}$ & $\begin{array}{l}-0.27 \\
(0.03)\end{array}$ & $\begin{array}{l}-0.24 \\
(0.03)\end{array}$ \\
\hline RE Quintiles & $\begin{array}{l}-0.28 \\
(0.01)\end{array}$ & $\begin{array}{l}-0.35 \\
(0.01)\end{array}$ & $\begin{array}{l}-0.25 \\
(0.02)\end{array}$ & $\begin{array}{l}-0.23 \\
(0.01)\end{array}$ \\
\hline Demand Quintiles & $\begin{array}{l}-0.29 \\
(0.01)\end{array}$ & $\begin{array}{l}-0.32 \\
(0.01)\end{array}$ & $\begin{array}{l}-0.24 \\
(0.01)\end{array}$ & $\begin{array}{l}-0.23 \\
(0.01)\end{array}$ \\
\hline Simulation Model & -0.12 & -0.26 & -0.37 & -0.37 \\
\hline \multicolumn{5}{|l|}{ Gas } \\
\hline Main Specification & $\begin{array}{l}-0.72 \\
(0.02)\end{array}$ & $\begin{array}{l}-0.65 \\
(0.02)\end{array}$ & $\begin{array}{c}-0.76 \\
(0.03)\end{array}$ & $\begin{array}{l}-0.77 \\
(0.01)\end{array}$ \\
\hline \multicolumn{5}{|c|}{ Specifications with time fixed effects } \\
\hline Hour FE & $\begin{array}{l}-0.74 \\
(0.02)\end{array}$ & $\begin{array}{l}-0.67 \\
(0.02)\end{array}$ & $\begin{array}{l}-0.77 \\
(0.03)\end{array}$ & $\begin{array}{l}-0.77 \\
(0.01)\end{array}$ \\
\hline Month FE & $\begin{array}{l}-0.73 \\
(0.02)\end{array}$ & $\begin{array}{l}-0.66 \\
(0.02)\end{array}$ & $\begin{array}{l}-0.76 \\
(0.03)\end{array}$ & $\begin{array}{l}-0.77 \\
(0.01)\end{array}$ \\
\hline MonthxYear FE & $\begin{array}{l}-0.73 \\
(0.02)\end{array}$ & $\begin{array}{l}-0.67 \\
(0.02)\end{array}$ & $\begin{array}{l}-0.76 \\
(0.03)\end{array}$ & $\begin{array}{l}-0.77 \\
(0.01)\end{array}$ \\
\hline \multicolumn{5}{|c|}{ Specifications with different threshold levels $\hat{\phi}$} \\
\hline$\hat{\phi}=0.7$ & $\begin{array}{l}-0.78 \\
(0.03)\end{array}$ & $\begin{array}{l}-0.66 \\
(0.01)\end{array}$ & $\begin{array}{l}-0.76 \\
(0.04)\end{array}$ & $\begin{array}{l}-0.76 \\
(0.01)\end{array}$ \\
\hline$\hat{\phi}=0.8$ & $\begin{array}{c}-0.68 \\
(0.02)\end{array}$ & $\begin{array}{c}-0.68 \\
(0.02)\end{array}$ & $\begin{array}{c}-0.75 \\
(0.02)\end{array}$ & $\begin{array}{l}-0.78 \\
(0.02)\end{array}$ \\
\hline \multicolumn{5}{|c|}{ Flexible and semi-parametric specifications } \\
\hline Polynomials & $\begin{array}{l}-0.69 \\
(0.03)\end{array}$ & $\begin{array}{l}-0.61 \\
(0.03)\end{array}$ & $\begin{array}{l}-0.73 \\
(0.03)\end{array}$ & $\begin{array}{l}-0.76 \\
(0.03)\end{array}$ \\
\hline RE Quintiles & $\begin{array}{l}-0.72 \\
(0.01)\end{array}$ & $\begin{array}{l}-0.65 \\
(0.01)\end{array}$ & $\begin{array}{l}-0.75 \\
(0.02)\end{array}$ & $\begin{array}{l}-0.77 \\
(0.01)\end{array}$ \\
\hline Demand Quintiles & $\begin{array}{l}-0.71 \\
(0.01)\end{array}$ & $\begin{array}{l}-0.68 \\
(0.01)\end{array}$ & $\begin{array}{l}-0.76 \\
(0.01)\end{array}$ & $\begin{array}{l}-0.77 \\
(0.01)\end{array}$ \\
\hline Simulation Model & -0.88 & -0.74 & -0.63 & -0.63 \\
\hline
\end{tabular}

Notes: Table shows the replacement of fossil generation in MWh induced by one MWh of wind and solar power, respectively. Standard errors are shown in parentheses. Cheap Coal refers to periods in which the coal-to-gas price ratio is below the defined threshold; Fuel Switch to the remaining periods. 


$$
\begin{aligned}
q_{i t}= & \sum_{\tilde{\phi}}\left(\alpha_{\tilde{\phi}}+\beta_{1 w i \tilde{\phi}} w_{t}+\beta_{2 w i \tilde{\phi}} w_{t}^{2}+\beta_{3 w i \tilde{\phi}} w_{t}^{3}+\beta_{1 s i \tilde{\phi}} s_{t}+\beta_{2 s i \tilde{\phi}} s_{t}^{2}+\beta_{3 s i \tilde{\phi}} s_{t}^{3}+\right. \\
& \left.\beta_{4 i \tilde{\phi}} d_{t}+\beta_{5 i \tilde{\phi}} d_{t}^{2}+\beta_{6 i \tilde{\phi}} d_{t}^{3}+\beta_{7 i \tilde{\phi}} \phi_{t}+\beta_{8 i \tilde{\phi}} t e m p_{t}+\gamma_{\boldsymbol{i}} \boldsymbol{k}_{\boldsymbol{t}}+\gamma_{\boldsymbol{i}} \boldsymbol{V}_{\boldsymbol{t}}\right) I_{t \tilde{\phi}}+\epsilon_{i t}
\end{aligned}
$$

We calculate the average marginal replacement of coal and gas generation by RE production for each fuel price regime as the partial derivative of $q_{i t}$ and $r_{i t}$, which we evaluate at the sample average of renewable production $\bar{r}$ :

$$
\delta_{i r \tilde{\phi}}^{Q}=\frac{\partial q_{i t}}{\partial r_{i t}}=\beta_{1 r i \tilde{\phi}}+2 \beta_{2 r i \tilde{\phi}} \overline{r_{\tilde{\phi}}}+3 \beta_{3 r i \tilde{\phi}} \bar{r}_{\tilde{\phi}}^{2} \quad \forall \tilde{\phi}, i, r
$$

Table C.2 shows that the replacement effect of wind and solar on coal (gas) is slightly higher (lower) for the specification including polynomials as compared to the main specification given by equation (9).

\section{Appendix C.3.2. Semi-parametric: Coefficients vary by demand}

In this specification, we allow coefficients of wind and solar power and demand to vary flexibly by demand level dividing hourly demand into five separate bins corresponding to the quintiles of the demand distribution. This allows us to analyze to what extent our results depend on demand levels. With $\operatorname{Bin}_{p}\left(d_{t}\right)$ denoting the $\mathrm{p}^{\text {th }}$ demand quintile, we estimate:

$$
\begin{aligned}
q_{i t}= & \sum_{\tilde{\phi}}\left(\sum_{p=1}^{5} \operatorname{Bin}_{p}\left(d_{t}\right)\left[\alpha_{\tilde{\phi} p}+\beta_{1 w i \tilde{\phi} p} w_{t}+\beta_{1 s i \tilde{\phi} p} s_{t}+\beta_{2 i \tilde{\phi} p} d_{t}\right]+\right. \\
& \left.\beta_{3 i \tilde{\phi}} \phi_{t}+\beta_{4 i \tilde{\phi}} t e m p_{t}+\gamma_{i} \boldsymbol{k}_{\boldsymbol{t}}+\gamma_{\boldsymbol{i}} \boldsymbol{V}_{\boldsymbol{t}}\right) I_{t \tilde{\phi}}+\epsilon_{i t}
\end{aligned}
$$

We can then calculate the average marginal replacement effect as the mean of the bin-specific coefficients:

$$
\delta_{i r \tilde{\phi}}^{Q}=\frac{1}{5} \sum_{p=1}^{5} \operatorname{Bin}_{p}\left(d_{t}\right) \beta_{1 r i \tilde{\phi} p}
$$

Figure C.2 shows how the replacement effect depends on demand levels. We find that the results only vary slightly across demand levels. However, there is a larger variation in the case of solar as compared to wind and the difference in replacement impacts between the two regimes is most pronounced in the highest demand percentile, where solar is mostly active. In all cases, the semiparametric estimates of the replacement effect of wind and solar include the core estimate of the main specification (dotted lines).

\section{Appendix C.3.3. Coefficients vary by renewable energy generation}

Similarly, we estimate a semi-parametric model, where we allow the coefficients of wind and solar power and demand to vary flexibly by RE generation level. Here, we aggregate wind and solar power to total RE generation (re) 
Figure C.2. Impact of RE on fossil generation by demand quintile
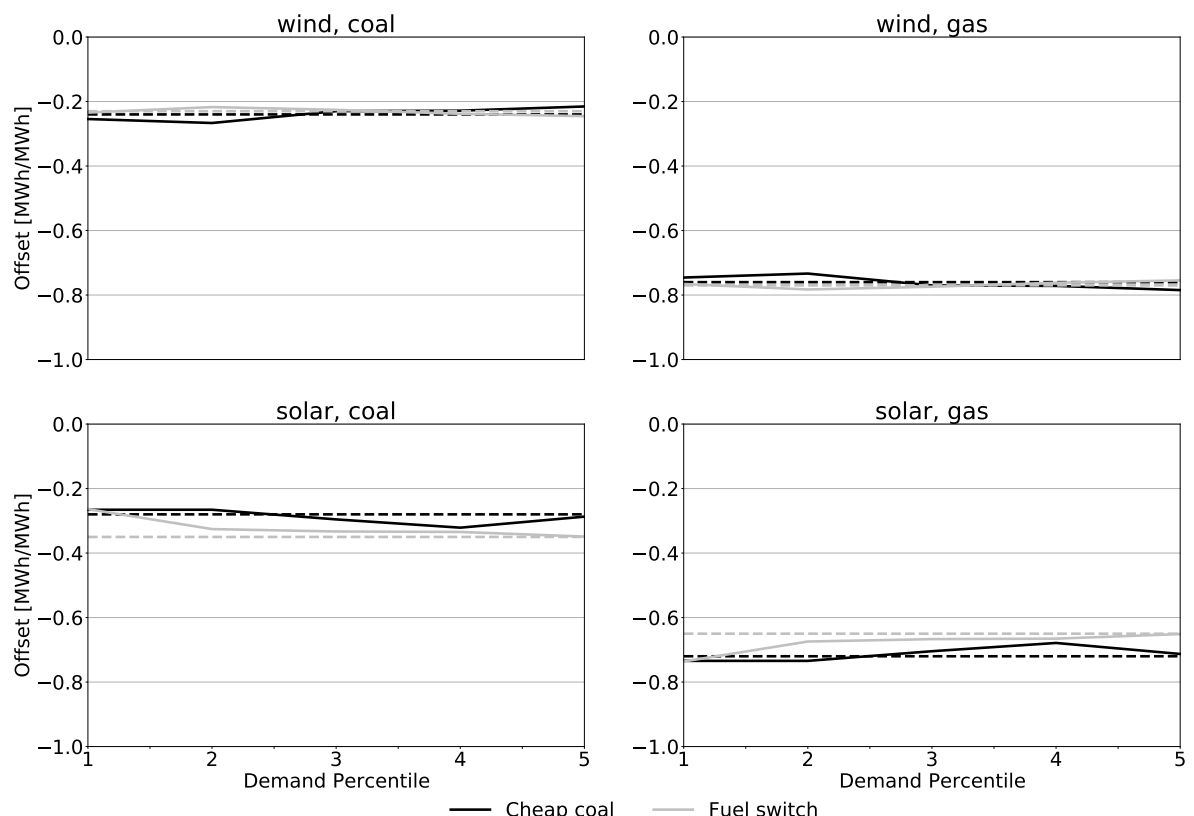

Notes: Dotted lines show the estimates of our main specification (equation 9).

and divide hourly $\mathrm{RE}$ generation into five separate bins corresponding to the quintiles of its distribution. With $\operatorname{Bin}_{p}\left(r e_{t}\right)$ as indicator representing the $\mathrm{p}_{\text {th }}$ renewable quintile, we estimate:

$$
\begin{aligned}
q_{i t}= & \sum_{\tilde{\phi}}\left(\sum_{p=1}^{5} \operatorname{Bin}_{p}\left(r e_{t}\right)\left[\alpha_{\tilde{\phi} p}+\beta_{1 w i \tilde{\phi} p} w_{t}+\beta_{1 s i \tilde{\phi} p} s_{t}+\beta_{2 i \tilde{\phi} p} d_{t}\right]+\right. \\
& \left.\beta_{3 i \tilde{\phi}} \phi_{t}+\beta_{4 i \tilde{\phi}} t e m p_{t}+\boldsymbol{\gamma}_{\boldsymbol{i}} \boldsymbol{k}_{\boldsymbol{t}}+\boldsymbol{\gamma}_{\boldsymbol{i}} \boldsymbol{V}_{\boldsymbol{t}}\right) I_{t \tilde{\phi}}+\epsilon_{i t}
\end{aligned}
$$

We can then calculate the average marginal replacement effect as the mean of bin-specific coefficients:

$$
\delta_{i r \tilde{\phi}}^{Q}=\frac{1}{5} \sum_{p=1}^{5} \operatorname{Bin}_{p}\left(r e_{t}\right) \beta_{1 r i \tilde{\phi} p}
$$

Figure C.3 shows how the replacement effect depends on the renewable generation level (given as the sum of solar and wind generation). As in the case of demand, results only slightly vary by $\mathrm{RE}$ quintile and the the semi-parametric estimates include the core estimate of our main specification (dotted lines). 
FiguRE C.3. Impact of RE on fossil generation by RE quintile
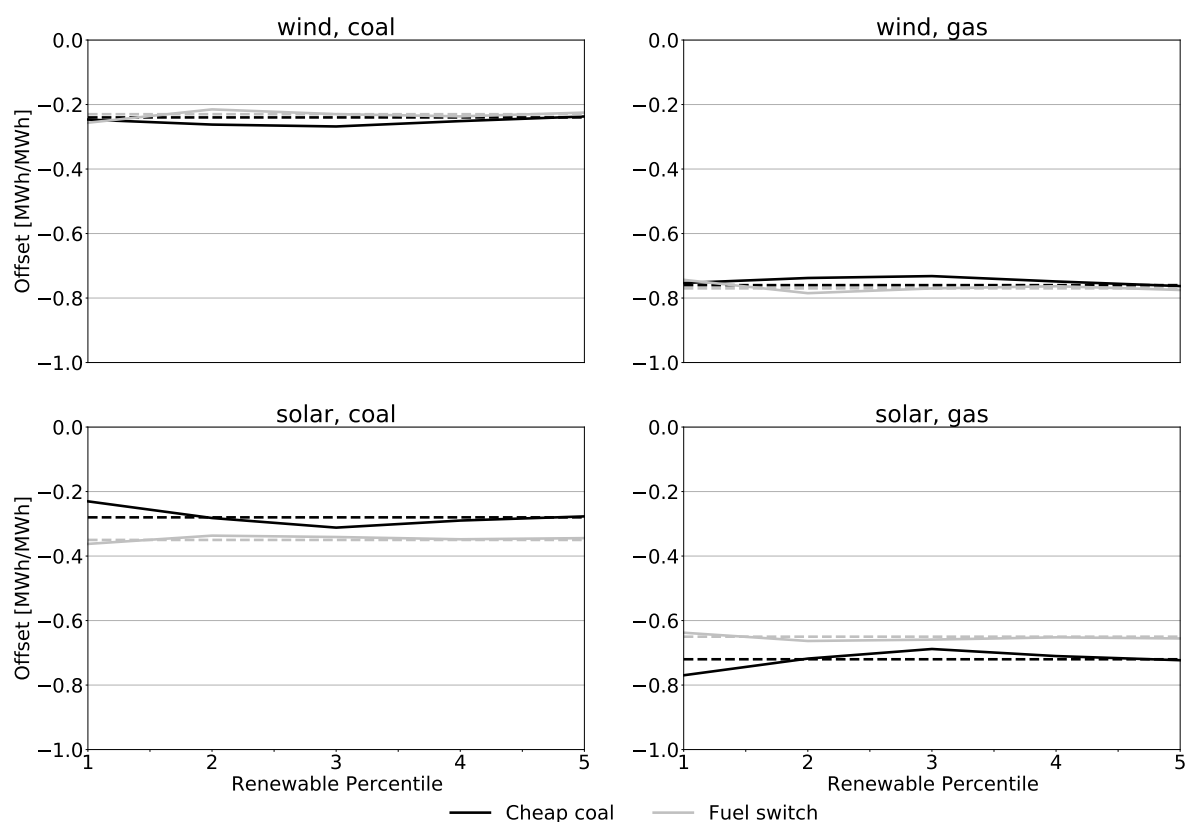

Notes: Dotted lines show the estimates of our main specification (equation 9).

Appendix C.4. Comparing results from empirical analysis and numerical model

In addition, we also provide the estimates resulting from our numerical model (described in Section 3.4). To this end, we simulate hourly market clearing under observed prices, available capacities, demand, and renewable generation. For each hour, we obtain the simulated electricity price as well as the marginal generator. We then calculate the optimal RE subsidies as averages of hourly effects for the two fuel price regimes.

Comparing the coal generation offsets of the main econometric specification and the numerical results, several insights emerge. First, the simulation results generally show a lower impact of solar on coal generation but a higher impact of wind on coal generation. Second, as in the econometric approach a fuel switch leads to an increased offset of coal generation by solar power. For wind power, however, the coal offsets by wind power is invariant to a fuel switch whereas the econometric approach shows a slight decrease. This confirms the intuition that due to the rather flat production profile of wind, the effect of a fuel switch on the generation offset of wind power is rather ambiguous.

Regarding the subsidy results of the numerical model (see Table 6), several things are noteworthy: First, compared to the estimates resulting from the regressions, subsidies are of similar size. Optimal feed-in tariffs are higher for both RE sources. Premiums are slightly lower in the case of solar and higher in the case of wind. Second, the relative adjustment of subsidies due to a fuel switch is consistent across the two approaches. Solar feed-ins decrease whereas premiums are increasing. For wind, feed-in and premiums decrease. Third, adjustments derived from the numerical model are somewhat larger than those derived from the econometric model. 
Download ZEW Discussion Papers from our ftp server:

http://ftp.zew.de/pub/zew-docs/dp/

or see:

https://www.ssrn.com/link/ZEW-Ctr-Euro-Econ-Research.html

https://ideas.repec.org/s/zbw/zewdip.html

$$
\text { // }
$$

IMPRINT

ZEW - Leibniz-Zentrum für Europäische Wirtschaftsforschung GmbH Mannheim

ZEW - Leibniz Centre for European

Economic Research

L 7,1 68161 Mannheim · Germany

Phone +49621 1235-01

info@zew.de·zew.de

Discussion Papers are intended to make results of ZEW research promptly available to other economists in order to encourage discussion and suggestions for revisions. The authors are solely responsible for the contents which do not necessarily represent the opinion of the ZEW. 